\title{
Innate Immune Response of Human Embryonic Stem Cell-Derived Fibroblasts and Mesenchymal Stem Cells to Periodontopathogens
}

\author{
Gopu Sriram, ${ }^{1,2}$ Vaishali Prakash Natu, ${ }^{1}$ Intekhab Islam, ${ }^{3}$ Xin Fu, ${ }^{4}$ \\ Chaminda Jayampath Seneviratne, ${ }^{1}$ Kai Soo Tan, ${ }^{1}$ and Tong Cao ${ }^{1,5,6}$ \\ ${ }^{1}$ Discipline of Oral Sciences, Faculty of Dentistry, National University of Singapore, Singapore \\ ${ }^{2}$ Institute of Medical Biology, Agency for Science, Technology and Research (A*STAR), Singapore \\ ${ }^{3}$ Discipline of Oral and Maxillofacial Surgery, Faculty of Dentistry, National University of Singapore, Singapore \\ ${ }^{4}$ Research Center of Plastic Surgery Hospital, Chinese Academy of Medical Sciences, Peking Union Medical College, Beijing, China \\ ${ }^{5}$ NUS Graduate School for Integrative Sciences and Engineering, Singapore \\ ${ }^{6}$ Tissue Engineering Program, Life Sciences Institute, National University of Singapore, Singapore
}

Correspondence should be addressed to Tong Cao; dencaot@nus.edu.sg

Received 26 January 2016; Revised 4 May 2016; Accepted 18 May 2016

Academic Editor: Zhaohui Ye

Copyright (C) 2016 Gopu Sriram et al. This is an open access article distributed under the Creative Commons Attribution License, which permits unrestricted use, distribution, and reproduction in any medium, provided the original work is properly cited.

\begin{abstract}
Periodontitis involves complex interplay of bacteria and host immune response resulting in destruction of supporting tissues of the tooth. Toll-like receptors (TLRs) play a role in recognizing microbial pathogens and eliciting an innate immune response. Recently, the potential application of multipotent stem cells and pluripotent stem cells including human embryonic stem cells (hESCs) in periodontal regenerative therapy has been proposed. However, little is known about the impact of periodontopathogens on hESCderived progenies. This study investigates the effects of heat-killed periodontopathogens, namely, Porphyromonas gingivalis and Aggregatibacter actinomycetemcomitans, on TLR and cytokine expression profile of hESC-derived progenies, namely, fibroblasts (hESC-Fib) and mesenchymal stem cells (hESC-MSCs). Additionally, the serotype-dependent effect of A. actinomycetemcomitans on hESC-derived progenies was explored. Both hESC-Fib and hESC-MSCs constitutively expressed TLR-2 and TLR-4. hESC-Fib upon exposure to periodontopathogens displayed upregulation of TLRs and release of cytokines (IL-1 $\beta$, IL-6, and IL-8). In contrast, hESC-MSCs were largely nonresponsive to bacterial challenge, especially in terms of cytokine production. Further, exposure of hESC-Fib to A. actinomycetemcomitans serotype $\mathrm{c}$ was associated with higher IL-8 production than serotype b. In contrast, the hESC-MSCs displayed no serotype-dependent response. Differential response of the two hESC progenies implies a phenotypedependent response to periodontopathogens and supports the concept of immunomodulatory properties of MSCs.
\end{abstract}

\section{Introduction}

Periodontitis is a chronic inflammatory disease of the tooth supporting tissues which is accompanied by tissue destruction, weakening of tooth support, and eventually loss of tooth $[1,2]$. It involves complex interplay of bacteria and host immune responses that ultimately lead to progressive destruction of the periodontium [3, 4]. Periodontopathic Gram-negative bacteria including Porphyromonas gingivalis (P. gingivalis) and Aggregatibacter actinomycetemcomitans
(A. actinomycetemcomitans) (previously known as Actinobacillus actinomycetemcomitans) have been strongly implicated in periodontitis $[5,6]$. Various components of these periodontopathogens, such as lipopolysaccharides (LPS), lipoproteins, and fimbriae, interact with the host through various pattern-recognition receptors $[7,8]$. Toll-like receptors (TLRs) are a family of pattern-recognition receptors evolved to detect various components of pathogens and have various downstream effects [9]. This involves activation of intracellular signaling cascade which stimulates transcription 
factors which finally leads to inflammatory cytokine expression, activation of immune cells, migration of leukocytes, and osteoclastogenesis [10]. Among the TLRs, TLR-2 and TLR-4 function as the principal innate sensors for cell wall components of Gram-negative bacteria in mammals and are considered crucial in the progress of periodontitis [11, 12]. TLR-2 and TLR-4 stimulation leads to activation of proinflammatory cytokines and chemokines which initiates the inflammatory process $[13,14]$. Cell wall components of $P$. gingivalis and $A$. actinomycetemcomitans stimulate, via TLR2 and TLR-4, the production of proinflammatory cytokines like interleukins IL- $1 \beta$ and IL- 6 which can induce production of matrix metalloproteinases and mediate alveolar bone resorption [15].

The goal of periodontal therapy is to halt the disease process and promote regeneration of the lost periodontal tissues. Currently available treatment modalities result in improved clinical outcomes; however, they are insufficient to achieve complete periodontal regeneration [16]. Currently, various biomaterial and/or cell-based approaches for formation and regeneration of periodontal tissues are explored (excellently reviewed elsewhere [16-18]). Recently, multipotent stem cells derived from various orodental tissues and pluripotent stem cells including human embryonic stem cells (hESCs) have been proposed as a promising source of cells for such cell-based periodontal regenerative therapies [1921]. Previous studies on miniature pigs have shown that local cellular therapy with autologous and allogeneic periodontal ligament stem cells (PDL-SCs) is associated with improved periodontal tissue regeneration $[22,23]$. MSCs are proposed to possess immunomodulatory properties through secretion of a host of soluble factors and/or direct cell-cell contact. The immunomodulatory properties of MSCs might offer a promising approach for periodontal regeneration. However, precise mechanisms are poorly understood, which limit the clinical application of MSCs.

hESCs are a potential source of stem cells due to their ability to self-renew and differentiate into virtually any cell type of the human body [24, 25]. Further, hESCs could be utilized to generate unlimited numbers of healthy and functional fibroblasts and mesenchymal stem cells (MSCs) that lack prior exposure to periodontopathogens. Recently, we [26-30] have developed methods to differentiate hESCs to fibroblasts and mesenchymal stem cells (MSCs). However, the potential impact of periodontopathogens on these hESCderived progenies remains poorly understood. Until now, little is known about the ability of hESC-derived progenies to express TLRs for sensing bacterial pathogens and their influence on cytokine secretory profile. Thus, a better understanding of the effects of exposure to periodontopathogens on TLR and cytokine expression by hESC-derived progenies could be crucial for their successful application.

In this study, we sought to comparatively investigate the effects of heat-killed $P$. gingivalis and A. actinomycetemcomitans on TLR and cytokine expression profile of human periodontal ligament fibroblasts (hPLFs) and hESC-derived progenies, namely, fibroblasts (hESC-Fib) and MSCs (hESCMSCs). Further, we investigated the influence of $A$. actinomycetemcomitans serotypes on TLR and cytokine expression profiles in order to explore strain-dependent effect within the same bacterial species.

\section{Materials and Methods}

2.1. Culture of hESCs. In this study, H1-hESCs (WiCell Research Institute, Madison, WI) were cultured on mitomycin-C inactivated-murine embryonic fibroblasts (MEFs) using hESC medium as described previously [31, 32]. Briefly, the hESC medium consisted of Dulbecco's modified Eagle's medium (DMEM)/Ham's F12 (1:1) supplemented with 20\% Knockout Serum Replacement (KO-SR, Gibco), $1 \%$ (vol/vol) nonessential amino acids, $1 \mathrm{mM}$ L-glutamine (Gibco), $4 \mathrm{ng} / \mathrm{mL}$ basic fibroblast growth factor (bFGF, Invitrogen), and $0.1 \mathrm{mM} \beta$-mercaptoethanol (Sigma). Media were changed every other day and passaged every 6-7 days using $1 \mathrm{mg} / \mathrm{mL}$ collagenase type IV (Gibco) for 5 minutes, followed by manual dissociation to small clumps and seeding onto MEF-seeded plates.

2.2. Differentiation of hESCs to Fibroblast-Like Cells. Fibroblast-like cells generated from hESCs are termed hESCFib (hESC-derived fibroblast-like cells) and were generated by methods described previously [26, 27]. Confluent H1hESC colonies were detached from the feeder layer using collagenase type IV $(1 \mathrm{mg} / \mathrm{mL})$. Large cell aggregates were broken up and replated in EB media [DMEM/F12 supplemented with $20 \% \mathrm{KO}-\mathrm{SR}, 1 \%$ (vol/vol) nonessential amino acids, $1 \mathrm{mM}$ L-glutamine, and $0.1 \mathrm{mM} \beta$-mercaptoethanol] in ultralow-attachment plates (Corning). After 24 hours, the suspended hESC clumps formed free-floating spheroidal aggregates or embryoid bodies (EBs). The culture medium was changed every 2 days. After 5 days, EBs were harvested and plated onto gelatin-coated plates in fibroblast medium [DMEM (high glucose) supplemented with 10\% fetal bovine serum (FBS, Biowest), $1 \mathrm{mM}$ L-glutamine, and penicillin/streptomycin (100 U/mL and $100 \mathrm{mg} / \mathrm{mL}$, resp.)]. After 15 days, the EB outgrowths were subcultured using TrypLE $^{\mathrm{TM}}$ Express (Gibco). After three such subcultures, the EB outgrowths attained homogenous population of spindleshaped cells. These cells are termed hESC-Fib and were designated as passage 0 . Passages 5-8 hESC-Fib were used in all subsequent experiments.

\subsection{Differentiation of hESCs to MSC-Like Cells. MSC-like} cells generated from hESCs are termed hESC-MSCs and were generated by methods described previously [28, 30]. hESCs were differentiated to hESC-MSCs using a two-step process involving EB formation, followed by outgrowth of EBs over gelatin-coated plates as described above. Briefly, H1-hESCs colonies were dissociated into small clumps after 15-20 minutes of incubation with $1 \mathrm{mg} / \mathrm{mL}$ collagenase type IV and then transferred to ultralow-attachment plates in EB media. After 7 days, EBs were harvested and plated onto gelatin-coated plates in MSC induction medium [DMEM (low glucose) supplemented with $10 \%$ FBS, $1 \mathrm{mM} \mathrm{L}$-glutamine, and $1 \%$ penicillin/streptomycin]. After 2 weeks, the EB outgrowths were subcultured using TrypLE Express. After the 2nd passage, the cells were maintained in MSC differentiation medium 
(PromoCell). The differentiated hESCs attained homogenous population of spindle-shaped cells. These are termed hESCMSCs and were designated as passage 0 . Passages 4-8 hESCMSCs were used in all subsequent experiments.

\subsection{Culture of Human Periodontal Ligament Fibroblasts.} Pooled primary human periodontal ligament fibroblasts (hPLFs) were obtained from a commercial source (ScienCell Research Laboratories) and were cultured as previously described $[33,34]$. Briefly, the hPLFs were cultured in fibroblast medium [DMEM (high glucose) supplemented with $10 \%$ fetal bovine serum, $1 \mathrm{mM}$ L-glutamine, and $1 \%$ penicillin/ streptomycin]. Passages 4-6 hPLFs were used in all subsequent experiments.

2.5. Culture of Periodontopathogens. P. gingivalis (ATCC W50), A. actinomycetemcomitans serotype b (ATCC 700685, JP2 clone), and A. actinomycetemcomitans serotype c (ATCC 33384) were obtained from American Type Culture Collection (ATCC). P. gingivalis was cultured on trypticase soy agar (TSA) with 5\% sheep blood agar (Oxoid) and incubated at $37^{\circ} \mathrm{C}$ in an anaerobic chamber (Don Whitley Scientific) while $A$. actinomycetemcomitans was cultured on brain heart infusion (BHI) agar (Acumedia) and incubated at $37^{\circ} \mathrm{C}$ with $5 \% \mathrm{CO}_{2}$. Broth cultures of $P$. gingivalis and A. actinomycetemcomitans were prepared by inoculating an isolated bacterial colony into BHI broth supplemented with yeast extract (Acumedia), hemin (Sigma), and vitamin K (Sigma) as previously described [35] and incubated as described above for 24 hours. Bacterial pellet was washed twice with sterile phosphate buffered saline (PBS) before resuspending in sterile water. Heat-killed bacteria $(\mathrm{HKB})$ were prepared by heating at $60^{\circ} \mathrm{C}$ for 30 minutes and aliquots were stored at $-20^{\circ} \mathrm{C}$.

2.6. Bacterial Challenge Assays. The cells (hESC-Fib, hESCMSCs, and hPLFs) were seeded in 6/96-well plates and grown in respective medium for 2 days till they reached a subconfluent stage. Each well of fibroblasts was subjected to bacterial challenge ( $P$. gingivalis and two different serotypes of $A$. actinomycetemcomitans) with a multiplicity of infection (MOI) of $1: 100$ (cells : bacteria) and incubated at $37^{\circ} \mathrm{C}$ with $5 \% \mathrm{CO}_{2}$ for 24 to 48 hours. Culture wells without bacterial challenge were used as control. Morphology of the cells was checked for abnormalities or cell death using phase-contrast microscopy. The metabolic activity of the cells was assayed using MTS assay after 24 and 48 hours of bacterial challenge. For transcript and protein analysis, the cells were challenged with bacteria for 24 hours. The culture supernatants were harvested and stored at $-80^{\circ} \mathrm{C}$ for protein assays. Following this, the cells were lysed and used for RNA extraction using RNeasy mini kit (Qiagen) as per the manufacturer's instructions.

2.7. Phenotyping of hESC-MSCs. The phenotype of hESCMSCs was characterized using flow cytometry and the following monoclonal antibodies: anti-CD31-APC (Miltenyi Biotec), anti-CD44-FITC (BD Pharmingen), anti-CD45FITC (BD Pharmingen), anti-CD73-APC (Miltenyi Biotec),
anti-CD90-FITC (BD Pharmingen), anti-CD105-PE (eBioscience), HLA-ABC-APC (BD Pharmingen), and HLA-DRFITC (BD Pharmingen). Briefly, the cells were dissociated and suspended in FACS buffer ( $1 \mathrm{x}$ PBS/0.5\% BSA) and nonspecific binding blocked with FcR blocking agent (Miltenyi Biotec) for 10 minutes at $4^{\circ} \mathrm{C}$. For labeling cell surface antigens, the cells were incubated with the abovementioned fluorescent conjugated antibodies for 10 minutes at $4^{\circ} \mathrm{C}$. After antibody labeling, data was acquired using Dako Cytomation CyAn ADP and analyzed using FlowJo v7.6.5 (Tree Star).

\subsection{Real-Time Reverse Transcriptase Polymerase Chain Reac-} tion (Real-Time RT-PCR). Harvested mRNA was reverse transcribed using iScript ${ }^{\mathrm{TM}}$ cDNA synthesis kit (Bio-Rad) according to the manufacturer's instructions. Real-time RTPCR was performed in triplicate using Fast SYBR Green PCR master mix (Applied Biosystems) and processed on StepOnePlus Real-Time PCR System (Applied Biosystems) as per the manufacturer's instructions. Briefly, after a $20 \mathrm{sec}$ activation step at $95^{\circ} \mathrm{C}, 40$ cycles of a two-step PCR were run which consisted of denaturation at $95^{\circ} \mathrm{C}$ for $3 \mathrm{sec}$, followed by an annealing and extension step at $60^{\circ} \mathrm{C}$ for $30 \mathrm{sec}$. Further, the PCR products were subjected to melt curve analysis to exclude the generation of nonspecific PCR products. The expression levels of target genes were quantified by normalization against corresponding endogenous reference $\beta$-ACTIN and expressed as fold change relative to respective control samples using the $\Delta \Delta \mathrm{C}_{\mathrm{T}}$ method. For presenting the constitutive expression of respective genes, relative quantity was calculated with $\beta$-ACTIN as a reference, by using the formula $2^{\left(-\left[\mathrm{C}_{\mathrm{TGENE}}-\mathrm{C}_{\mathrm{T} \beta \text {-ACTIN }}\right]\right)}$. Details of primer sequences used in this study are presented in Table 1 . The results are presented as mean \pm standard deviations of three independent experiments.

2.9. Cytokine Analysis. Enzyme linked immunosorbent assays (ELISA) were performed to determine the protein levels of IL-6 and IL-8 using the respective ELISA kits (R\&D Systems) according to the manufacturer's protocol. Prior to the ELISA, the culture supernatants were centrifuged to pellet the cellular and bacterial remains. The supernatants were harvested, diluted using dilution buffer supplied with the kits, and used for the protein estimation. The results are presented as mean \pm standard deviations of three independent experiments.

2.10. MTS Assay. This assay was used to determine the metabolic activity of the cells after addition of bacteria. 96-well plates were seeded with the cells and cultured in respective medium for 24 hours. Subsequently, bacteria were added to the wells at an MOI of 1:100 (cells : bacteria). Wells without the bacteria served as control. After 24 and 48 hours of bacterial challenge, media were removed, washed with PBS, and replaced with MTS [(3-(4,5-dimethylthiazol2-yl)-5-(3-carboxymethoxyphenyl)-2-(4-sulfophenyl)-2Htetrazolium)] reagent (Promega) and incubated at $37^{\circ} \mathrm{C}$ as per the manufacturer's instructions. Following incubation 
TABLE 1: Primer sequences used for real-time RT-PCR.

\begin{tabular}{|c|c|c|c|}
\hline Gene & Description & Primer sequence & Product length \\
\hline$\beta-A C T I N$ & Actin, beta & $\begin{array}{l}\text { F: CCAAGGCCAACCGCGAGAAGATGAC } \\
\text { R: AGGGTACATGGTGGTGCCGCCAGAC }\end{array}$ & $587 \mathrm{bp}$ \\
\hline OCT4 & $\begin{array}{l}\text { Octamer-binding transcription factor } 4 \\
\text { POU class } 5 \text { homeobox } 1 \text { (POU5F1) }\end{array}$ & $\begin{array}{l}\text { F: CGTGAAGCTGGAGAAGGAGAAGCTG } \\
\text { R: AAGGGCCGCAGCTTACACATGTTC }\end{array}$ & $247 \mathrm{bp}$ \\
\hline SOX2 & SRY- (sex determining region Y-) Box 9 & $\begin{array}{l}\text { F: CCGCATGTACAACATGATGG } \\
\text { R: CTTCTTCATGAGCGTCTTGG }\end{array}$ & $370 \mathrm{bp}$ \\
\hline$P 4 H \beta$ & Prolyl- 4-hydroxylase, beta subunit & $\begin{array}{l}\text { F: GTCTTTGTGGAGTTCTATGCCC } \\
\text { R: GTCATCGTCTTCCTCCATGTCT }\end{array}$ & 338 bp \\
\hline COL1A1 & Collagen type I, alpha-1 & $\begin{array}{l}\text { F: GAACGCGTGTCAATCCCTTGT } \\
\text { R: GAACGAGGTAGTCTTTCAGCAACA }\end{array}$ & $91 \mathrm{bp}$ \\
\hline COL $3 A 1$ & Collagen type III, alpha-1 & $\begin{array}{l}\text { F: AACACGCAAGGCTGTGAGACT } \\
\text { R: GCCAACGTCCACACCAAATT }\end{array}$ & $88 \mathrm{bp}$ \\
\hline$R U N X 2$ & Runt-related transcription factor 2 & $\begin{array}{l}\text { F: TGAGAGCCGCTTCTCCAACC } \\
\text { R: GCGGAAGCATTCTGGAAGGA }\end{array}$ & $266 \mathrm{bp}$ \\
\hline$I L-1 \beta$ & Interleukin-1-beta & $\begin{array}{l}\text { F: AAGCTGAGGAAGATGCTG } \\
\text { R: ATCTACACTCTCCAGCTG }\end{array}$ & $390 \mathrm{bp}$ \\
\hline$I L-6$ & Interleukin-6 (interferon, beta 2) & $\begin{array}{l}\text { F: TGCGTCCGTAGTTTCCTTCT } \\
\text { R: GCCTCAGACATCTCCAGTCC }\end{array}$ & $141 \mathrm{bp}$ \\
\hline$I L-8$ & Interleukin-8 & $\begin{array}{l}\text { F: GGTGCAGTTTTGCCAAGGAG } \\
\text { R: TTCCTTGGGGTCCAGACAGA }\end{array}$ & $183 \mathrm{bp}$ \\
\hline$O P G$ & Osteoprotegerin & $\begin{array}{l}\text { F: GCCTGGCACCAAAGTAAACG } \\
\text { R: TACGAAGCTGCTCGAAGGTG }\end{array}$ & 209 bp \\
\hline Osterix & Osterix, transcription factor $\mathrm{Sp} 7$ & $\begin{array}{l}\text { F: CTCTGGAGTCAGAGTAGGACTGT } \\
\text { R: CAAGGAGCCAGGCAGATGGA }\end{array}$ & $197 \mathrm{bp}$ \\
\hline$T L R-2$ & Toll-like receptor-2 & $\begin{array}{l}\text { F: GCCTCTCCAAGGAAGAATCC } \\
\text { R: TCCTGTTGTTGGACAGGTCA }\end{array}$ & $144 \mathrm{bp}$ \\
\hline$T L R-4$ & Toll-like receptor- 4 & $\begin{array}{l}\text { F: GGCAGCTCTTGGTGGAAGTT } \\
\text { R: ACAAGCACACTGAGGACCGA }\end{array}$ & $136 \mathrm{bp}$ \\
\hline$N A N O G$ & - & $\begin{array}{l}\text { F: TGATTTGTGGGCCTGAAGAAAA } \\
\text { R: GAGGCATCTCAGCAGAAGACA }\end{array}$ & $60 \mathrm{bp}$ \\
\hline VIMENTIN & - & $\begin{array}{l}\text { F: AGTCCACTGAGTACCGGAGAC } \\
\text { R: CATTTCACGCATCTGGCGTTC }\end{array}$ & $98 \mathrm{bp}$ \\
\hline
\end{tabular}

for 2 hours, the absorbance was measured at $490 \mathrm{~nm}$ using a microplate reader (Tecan).

2.11. Statistical Analysis. The results are presented as mean \pm standard deviation of three experiments. Statistical differences were evaluated by a two-tailed $t$-test or one-way ANOVA followed by Tukey's post hoc test. $p$ values $<0.05$ were considered statistically significant.

\section{Results}

3.1. Derivation and Characterization of hESC-Fib. To derive fibroblast-like cells from hESCs, H1-hESCs were differentiated through an EB outgrowth method under high-glucose culture conditions as previously described by us [26, 27, 32]. Undifferentiated hESCs exhibited compact colony morphology with defined borders (Figure 1(a)). After 24 hours of suspension culture, aggregates of hESC colonies formed EBs (Figure 1(b)). Adherent culture of EBs over gelatin-coated plates resulted in migration of fibroblast-like cells within $48 \mathrm{~h}$ of attachment. The migrating cells were called EB outgrowths, which proliferated gradually and reached confluence after 2 weeks of culture (Figure 1(c)). After 3 passages, the spindle-shaped fibroblast-like cells attained homogeneous morphology and were termed hESC-Fib (Figure 1(d)). Realtime RT-PCR analysis of the hESC-Fib demonstrated the downregulation of pluripotency markers (OCT4, SOX2, and $N A N O G)$ and upregulation of fibroblast-related markers (COL1A1, COL3A1, P4H $\beta$, and VIMENTIN) (Figure 1(e)). The hESC-Fib had spindle-shaped morphology similar to that of hPLFs (Figure 1(f)).

3.2. Differentiation and Characterization of hESC-MSCs. To generate MSC-like cells from hESCs, H1-hESCs were differentiated through a two-stage EB outgrowth method under low-glucose conditions as previously described [28, 30]. Briefly, EBs were generated by suspension culture of aggregates of hESCs (Figures 2(a) and 2(b)). After 10 days of differentiation under suspension culture, EBs were plated on gelatin-coated plates (Figure 2(c)). Upon adherent culture under low-glucose culture conditions, spindle-shaped cells migrated out from the EBs. These spindle-shaped EB 


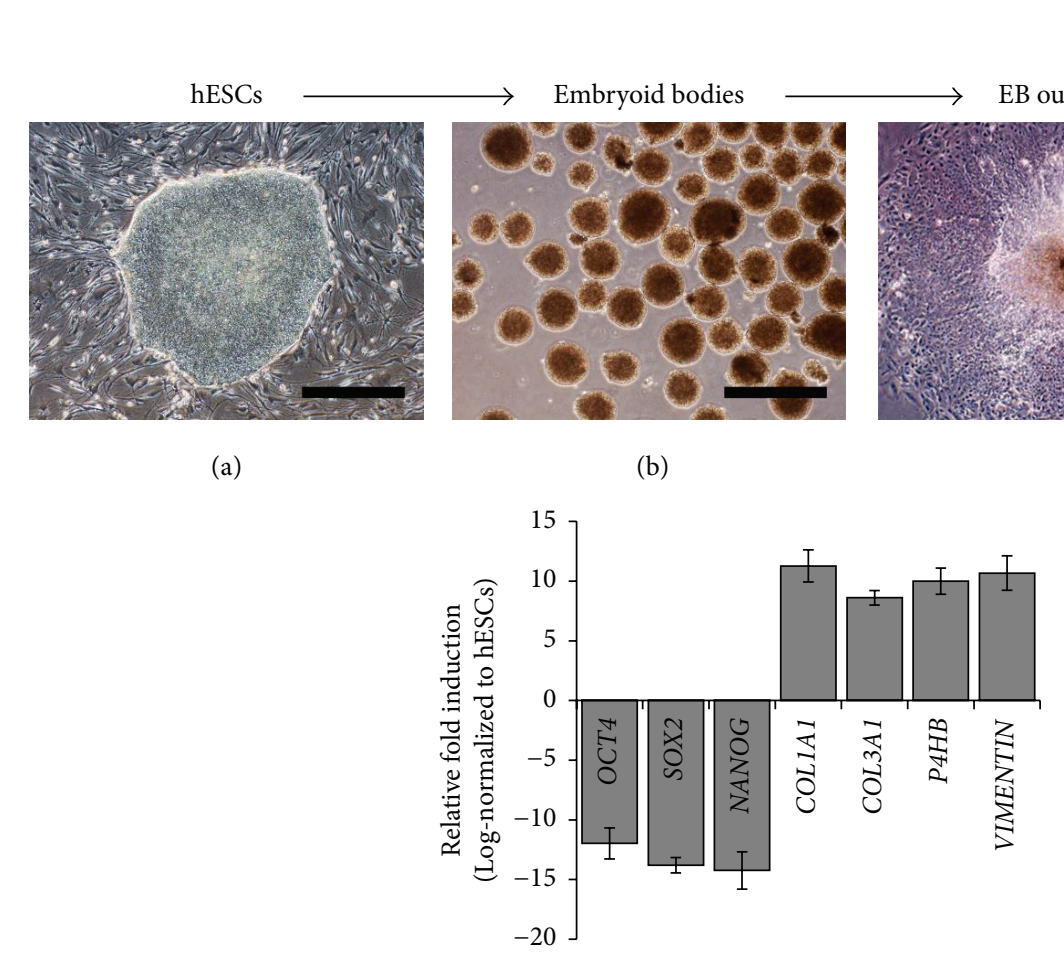

(a) (e)
High-glucose DMEM $+10 \%$ FBS

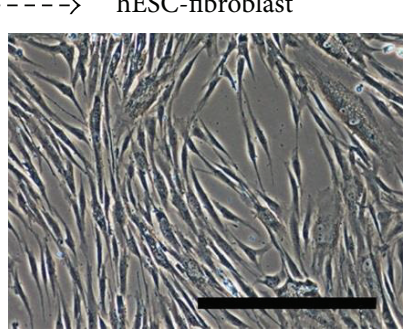

(d)

(c)

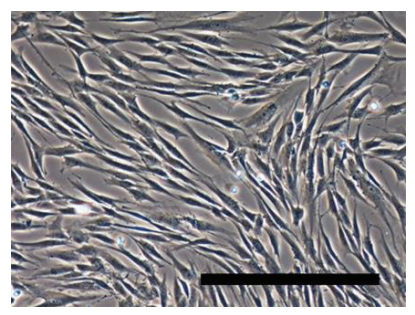

(f)

Figure 1: Differentiation of hESCs to hESC-Fib. (a-d) The photomicrographs demonstrate the differentiation of hESCs to embryoid bodies, embryoid body outgrowth, and hESC-Fib under high-glucose differentiation conditions. (e) Characterization of hESC-Fib by real-time RT-PCR for pluripotency (OCT4, SOX2, and NANOG) and fibroblast-related transcripts (COL1A1, COL3A1, P4H $\beta$, and VIMENTIN). (f) Photomicrograph shows the spindle-shaped hPLFs. Scale bar: $500 \mu \mathrm{m}$.

outgrowth cells were subcultured under low-glucose conditions for 2 passages before the cells attained homogeneous morphology and were termed hESC-MSCs (Figure 2(d)). The phenotype and multilineage differentiation ability of these hESC-MSCs have been characterized and published earlier $[28,30,36]$. Real-time RT-PCR analysis of the hESC-MSCs demonstrated the downregulation of transcripts related to pluripotency (OCT4, SOX2, and NANOG) and upregulation of mesenchymal (COL1A1, COL3A1) and osteogenic (RUNX2, OSTERIX, and OPG) transcripts (Figure 2(e)). Further, flow cytometry analysis markers of MSCs demonstrated expression of MSC-associated surface markers CD44 (99.7\%), CD73 (99.7\%), CD90 (96.4\%), and CD105 (99.6\%) and were negative for CD31 (1\%) and CD45 (1\%) (Figure 2(f)). Further, majority of hESC-MSCs (>99\%) displayed the expression of HLA class I molecule HLA-ABC at high levels but lacked the expression of HLA class II molecule HLA-DR (1\%) (Figure 2(f)).

3.3. Bacterial Challenge Does Not Affect Cellular Morphology and Viability. Cellular morphology, viability, and proliferation of hPLFs, hESC-Fib, and hESC-MSCs were assessed by phase-contrast microscopy and MTS assay after 24 and 48 hours of bacterial challenge. Fibroblast cultures devoid of bacterial challenge were used as negative control. The morphology of all the three cell types was not affected by exposure to P. gingivalis and A. actinomycetemcomitans (Figure 3(a)).
Based on MTS assay, hPLFs, hESC-Fib, and hESC-MSCs were viable and proliferative after 24 and 48 hours of challenge with all three strains of bacteria (Figure 3(b)).

3.4. Constitutive Expression of TLRs and Cytokines in Fibroblasts and MSCs. The expression profiles of TLRs in hESCs, fibroblasts, and MSCs were analyzed at mRNA level by realtime RT-PCR, while the profiles of cytokine expression were analyzed at transcript and protein levels using real-time RTPCR and ELISA. Real-time RT-PCR analysis demonstrated that hPLFs, hESCs, hESC-Fib, and hESC-MSCs constitutively expressed TLR-2 and TLR-4 (Figure 4(a)). Interestingly, hESCs expressed higher levels of TLR-2 and TLR-4. The hESC-derived progenies (hESC-Fib and hESC-MSCs) expressed relatively higher levels of TLR-4 than TLR-2.

Prior to investigation into the effect of bacterial challenge, basal expression levels of cytokines ( $I L-1 \beta, I L-6$, and $I L-8)$ in hESCs, hPLFs, hESC-Fib, and hESC-MSCs were quantitatively analyzed (Figure 4). Real-time RT-PCR analysis demonstrated that hESCs and hPLFs expressed low levels of all the three cytokines. hESC-Fib expressed low levels of $I L$ $1 \beta$ and $I L-6$ and moderate levels of $I L-8$. On the contrary, hESC-MSCs expressed low levels of $I L-1 \beta$ and $I L-6$ similar to hESC-Fib but extremely high levels of $I L-8$ (Figures 4(b) and 4(c)). Absolute quantification of IL- 6 and IL-8 secretion using ELISA shows significantly high levels of IL-6 and IL-8 secretion by hESC-MSCs compared to hPLFs and hESC-Fib, 


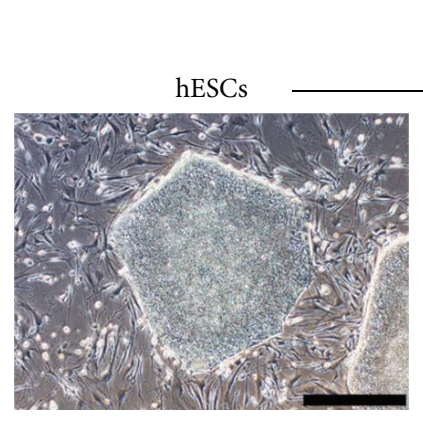

(a)

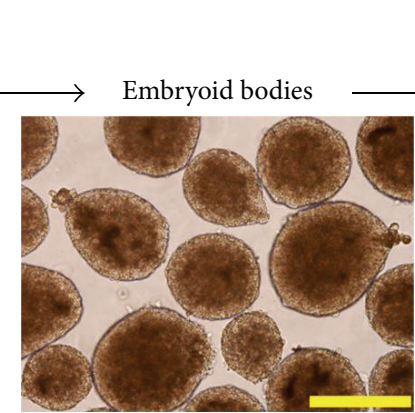

(b)

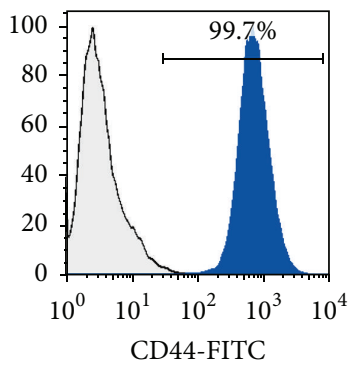

(c)
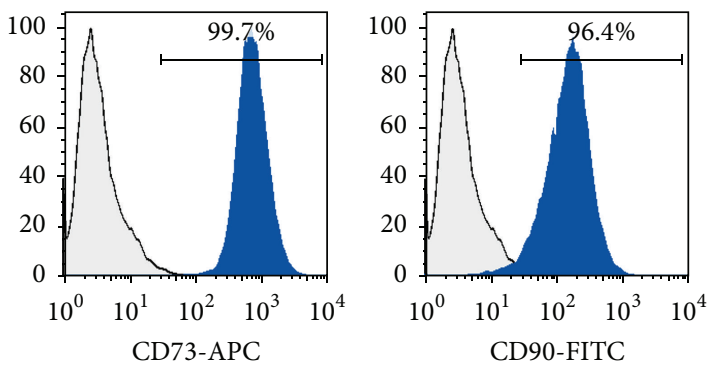

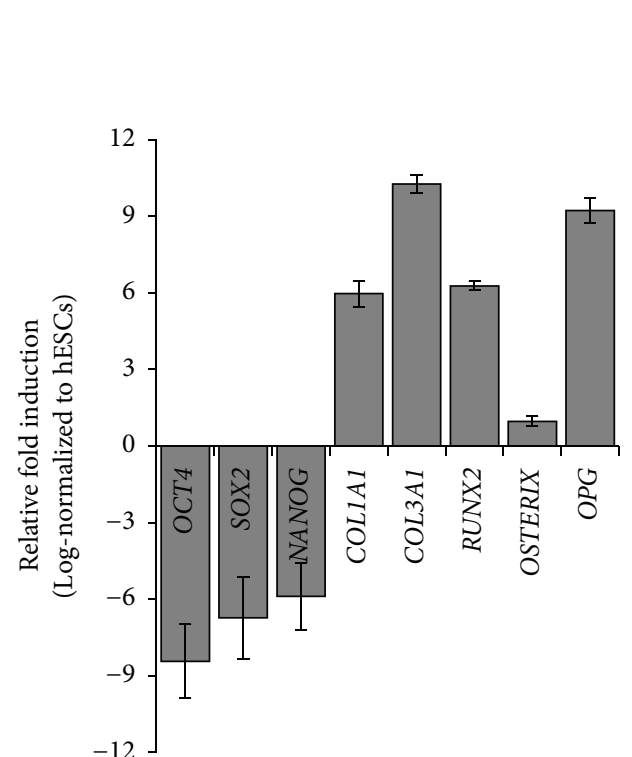

(e)
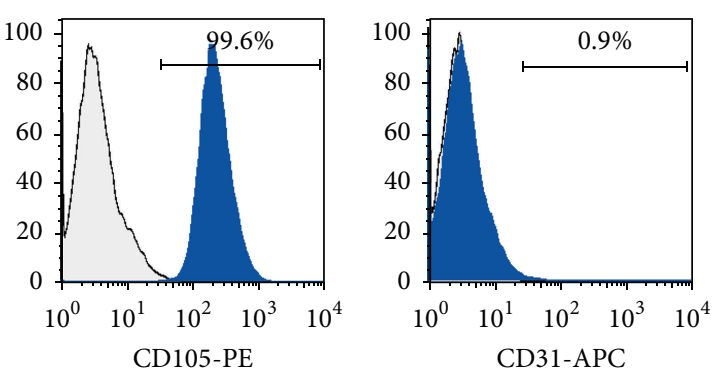

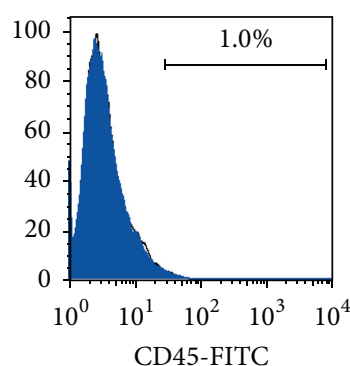

CD45-FITC

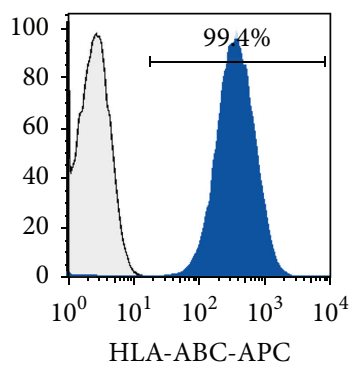

(f)

Figure 2: Differentiation of hESCs to hESC-MSCs. (a-d) The photomicrographs demonstrate the differentiation of hESCs to hESC-MSCs through embryoid bodies and embryoid body outgrowth under low-glucose differentiation conditions. (e) Characterization of hESC-MSCs by real-time RT-PCR for pluripotency (OCT4, SOX2, and NANOG) and mesenchymal (COL1A1, COL3A1) and osteogenic (RUNX2, OSTERIX, and $O P G$ ) lineage associated transcripts. (f) Flow cytometry characterization of hESC-MSCs for expression of surface markers. Scale bar in (a) and (c): $500 \mu \mathrm{m}$. Scale bar in (b) and (d): $200 \mu \mathrm{m}$.

while there was no significant difference in the cytokine levels secreted by hPLFs and hESC-Fib (Figure 4(d)).

3.5. Influence of Bacterial Challenge on TLR Expression in Fibroblasts and MSCs. To investigate the effect of bacterial challenge on TLR expression, hPLFs, hESC-Fib, and hESCMSCs were exposed to heat-killed $P$. gingivalis and two different serotypes of $A$. actinomycetemcomitans at an MOI of 1:100 for 24 hours. Unchallenged cells were used as negative control. Exposure to the three different Gramnegative bacteria induced significant upregulation of TLR2 expression in all the three cell types (Figure 5(a)). The fibroblast populations (hPLFs and hESC-Fib) exhibited $\sim 2$ fold increase in TLR-2 expression upon challenge with all the three Gram-negative bacteria, while the hESC-MSCs exhibited 5-7-fold increase in TLR-2 expression under similar conditions. Further, the three cell types exhibited differential $T L R-4$ expression after bacterial challenge. hPLFs exhibited 

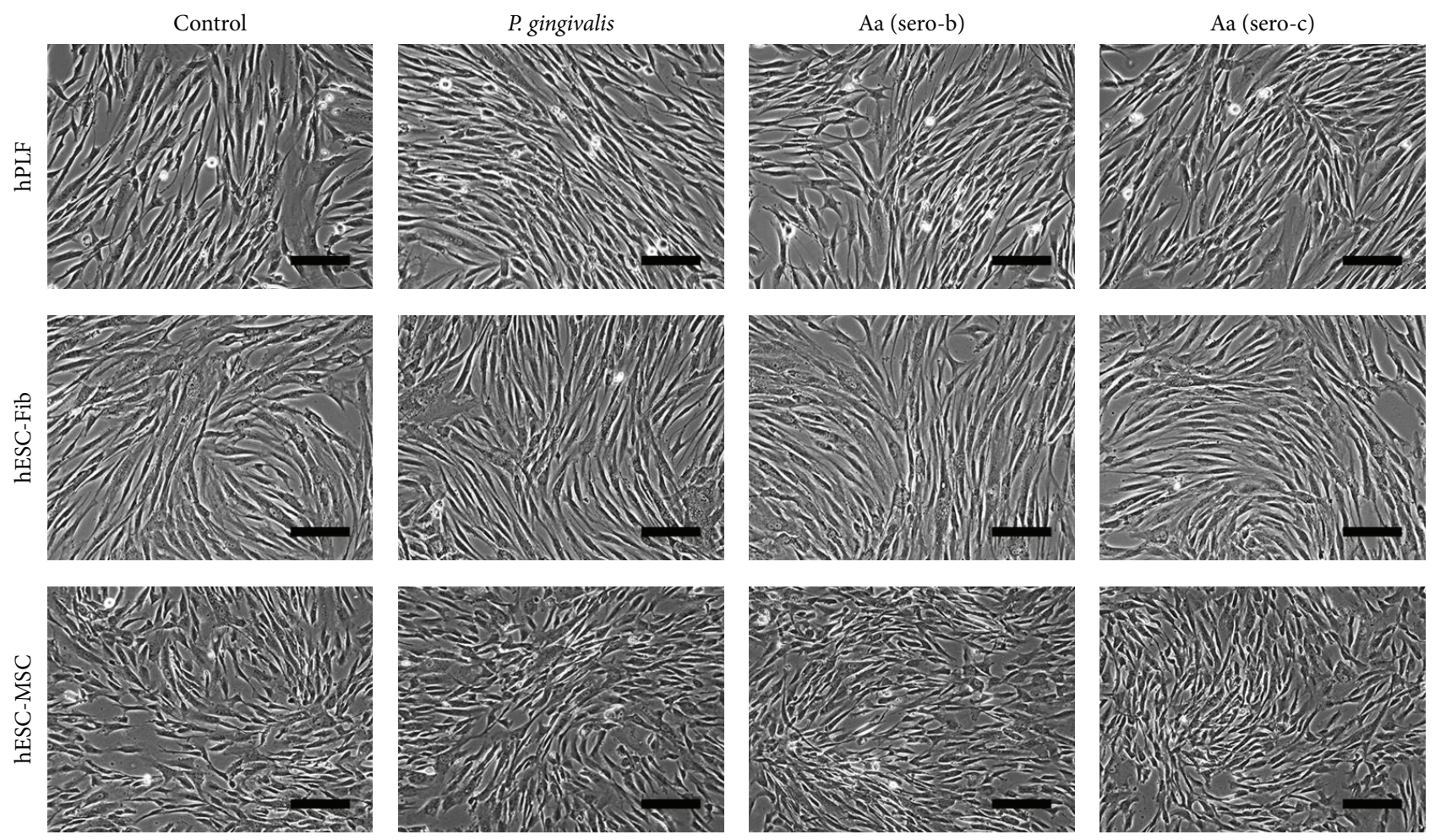

(a)
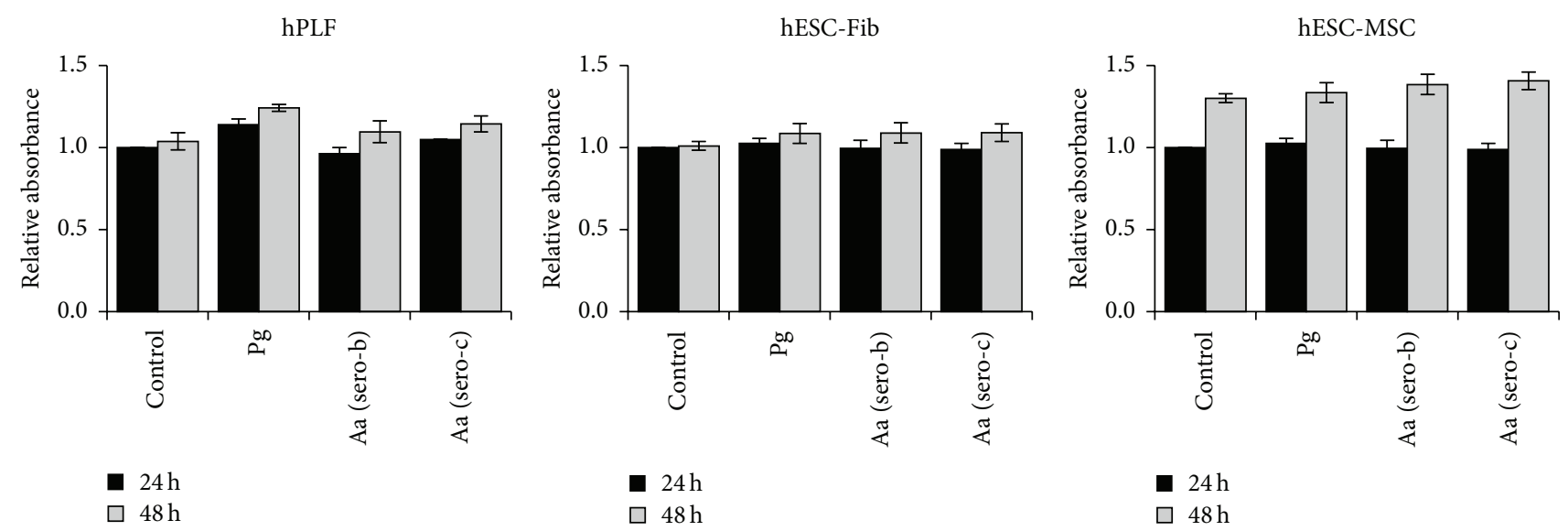

(b)

Figure 3: Viability and proliferation of hPLFs, hESC-Fib, and hESC-MSCs. (a) Morphology of control and treated groups after 48 hours of bacterial challenge. (b) Viability and proliferation of cells assessed by MTS assay after exposure to P. gingivalis (Pg) and two different serotypes of $A$. actinomycetemcomitans (Aa serotypes b and c) for 24 and 48 hours. Scale bar: $200 \mu \mathrm{m}$.

significant upregulation of TLR-4 expression upon exposure to $P$. gingivalis only, while in hESC-Fib all the three Gramnegative bacteria induced TLR-4 upregulation. However, hESC-MSCs displayed no significant change in TLR-4 expression upon exposure to all the three Gram-negative bacteria (Figure 5(b)).

3.6. Bacterial Challenge Induces Cytokine Expression in Fibroblasts, but Not in hESC-MSCs. Exposure of hPLFs to Gram-negative bacteria resulted in significant upregulation of all the three cytokines ( $I L-1 \beta, I L-6$, and $I L-8)$ (Figure 6).
Estimation of the amount of cytokines released into the culture media also showed a significant increase in production of IL-6 and IL-8 upon exposure to the Gram-negative bacteria (Figure 7). Similarly, exposure of hESC-Fib to Gram-negative bacteria resulted in significant upregulation of $I L-1 \beta, I L-6$, and $I L-8$ and increased secretion of IL- 6 and IL-8 (Figures 6 and 7). In contrast, exposure of hESC-MSCs to $P$. gingivalis had no significant effect on the expression of $I L-1 \beta, I L-6$, and $I L-8$. Similarly, exposure of hESC-MSCs to A. actinomycetemcomitans induced significant upregulation of $I L-1 \beta$ but had no effect on $I L-6$ and significantly downregulated 


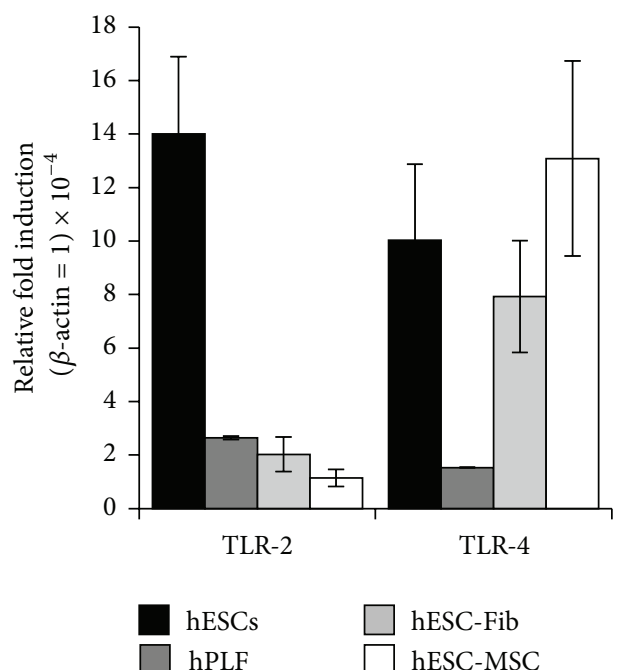

(a)

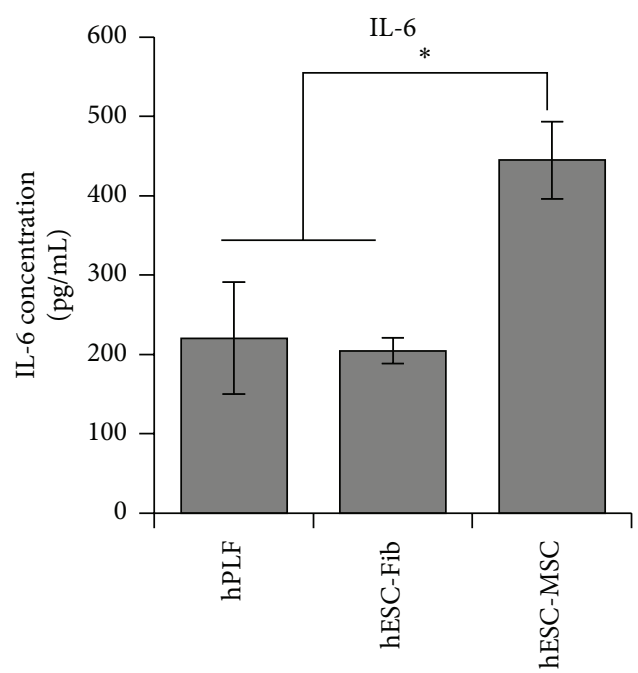

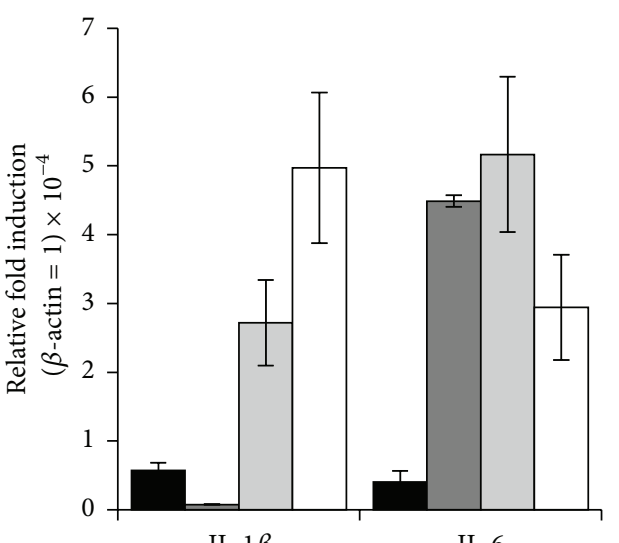

IL-1 $\beta$

IL-6

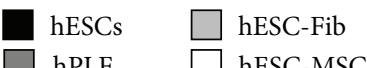

(b)

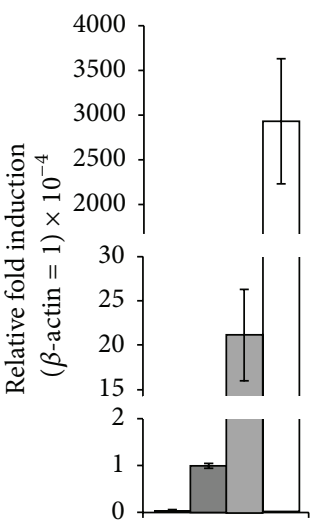

IL-8

hESCs

hPLF

hESC-Fib

hESC-MSC

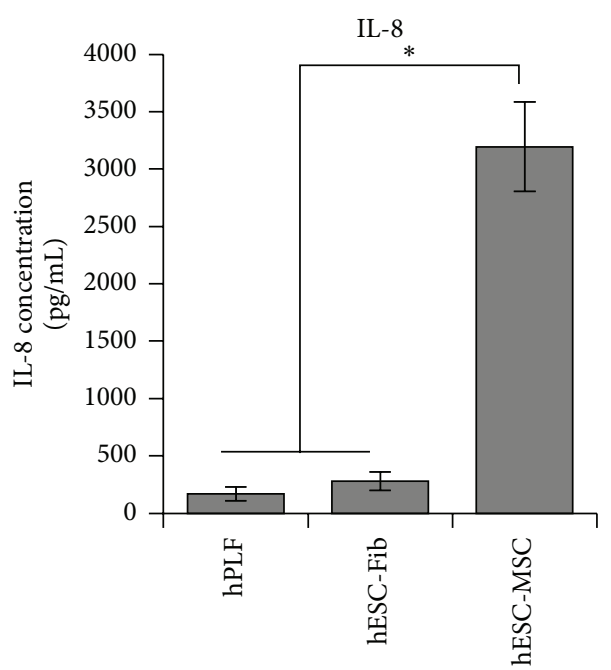

(d)

FIgURE 4: Basal expression profiles of TLR and cytokines in hESCs, hPLFs, hESC-Fib, and hESC-MSCs. Basal expression profiles of (a) TLR-2 and TLR- 4 and (b, c) IL-1 $\beta$, IL-6, and IL- 8 among hESCs, hPLFs, hESC-Fib, and hESC-MSCs as analyzed by real-time RT-PCR. The relative fold induction is relative to the respective transcript levels of $\beta$-actin. The $y$-axis in (c) is broken to enable visualization of the relative expression levels of IL-8 among the different cell types. (d) Basal levels of cytokine production in the culture supernatants (assayed using ELISA) from hPLFs, hESC-Fib, and hESC-MSCs. The production of IL- 6 and IL- 8 by hESCs was below detection limits. Values represent the means $\pm \mathrm{SD}$ of three experiments $\left({ }^{*} p<0.05\right)$.

IL-8 expression at transcript levels (Figure 6). However, quantification of cytokine secretion levels showed that all the three Gram-negative bacteria had no significant effect on the secretion of IL-6 and IL-8 in hESC-MSCs (Figure 7). The discrepancy in transcript and protein levels might be due to the high constitutive expression of cytokines by the hESC-MSCs. Though the bacterial challenge of hESC-MSCs is associated with TLR-2 upregulation, there is no effect on production of cytokines studies. Further studies on other inflammatory and anti-inflammatory cytokines like TGF $\beta$, TNF- $\alpha$, IL-10, and nitric oxide might shed more light on their response to bacterial challenge.
Overall, these results indicate the differential expression of cytokines upon exposure to Gram-negative bacteria depending on the cell type investigated. Further, the results highlight the distinct difference in the response of hESCMSCs compared to the fibroblast phenotypes and perhaps support the immunomodulatory properties of MSCs.

3.7. Effect of A. actinomycetemcomitans Serotype on TLR and Cytokine Expression. The influence of A. actinomycetemcomitans serotypes on TLR expression was compared in order to investigate strain-dependent effect within the same bacterial 

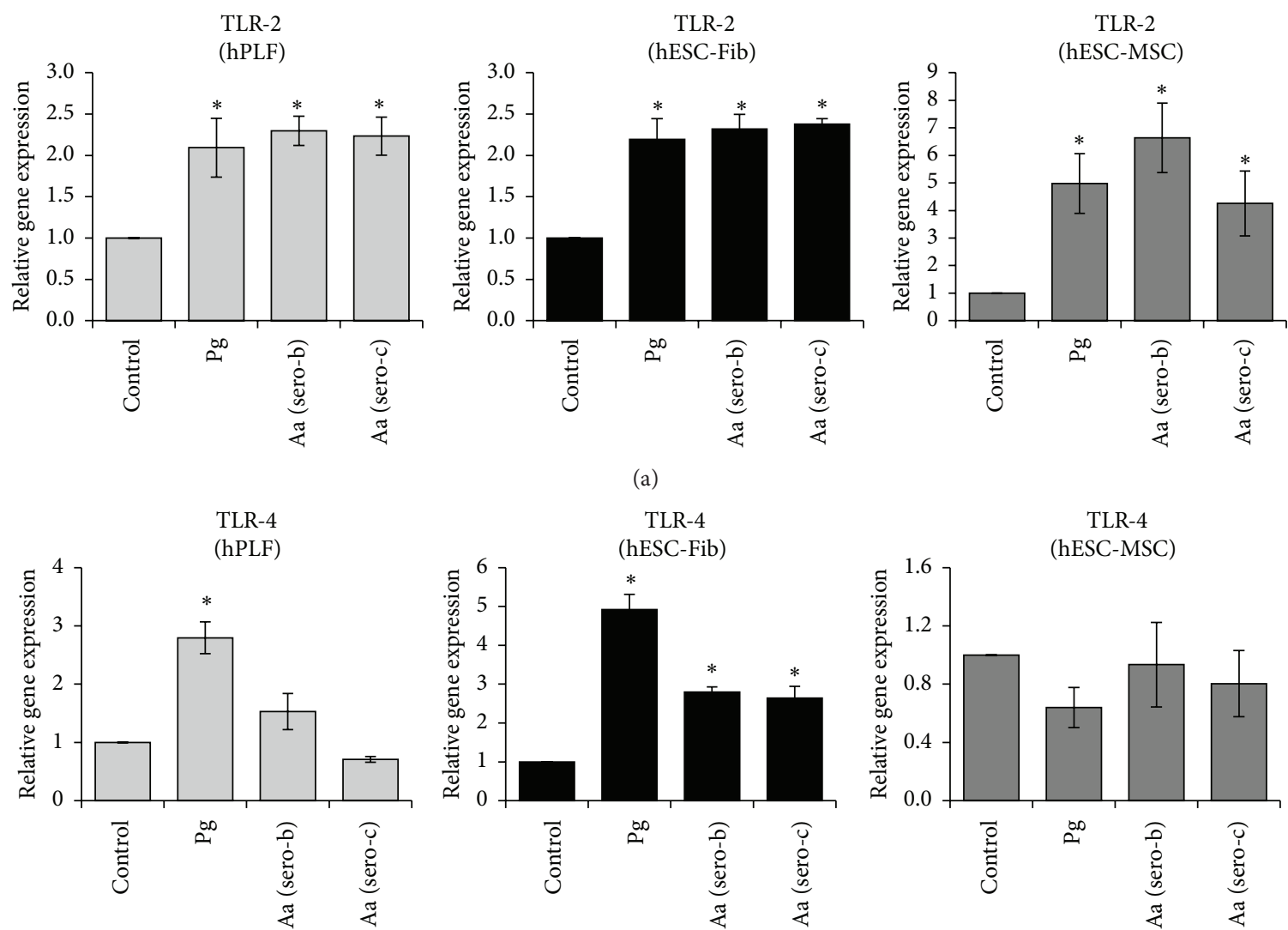

(b)

FIgURE 5: Transcript expression profiles of TLR-2 (a) and TLR-4 (b) among hPLFs, hESC-Fib, and hESC-MSCs in response to exposure to P. gingivalis $(\mathrm{Pg})$ and two different serotypes of A. actinomycetemcomitans (Aa serotypes $\mathrm{b}$ and $\mathrm{c}$ ). The transcript levels were normalized to the respective $\beta$-actin levels and to the untreated control sample. Values represent the means $\pm \mathrm{SD}$ of three experiments $\left({ }^{*} p<0.05\right.$ versus untreated control).

species. The cells were challenged with A. actinomycetemcomitans serotype b (Aa ATCC 700685) or A. actinomycetemcomitans serotype c (Aa ATCC 33384). hPLFs and hESCderived progenies displayed no significant difference between the two $A a$ strains in activating TLR-2 and TLR-4 expression (Figure 5).

Interestingly, there were striking differences among the two serotypes of $A$. actinomycetemcomitans in cytokine production. Aa serotype $\mathrm{c}$ induced significant upregulation of $I L-1 \beta, I L-6$, and $I L-8$ compared to $A a$ serotype b in hPLFs (Figure 6). Absolute quantification of cytokine production also revealed significantly higher production of IL-6 and IL8 by hPLFs exposed to $A a$ (serotype c) (Figure 7). Similarly, exposure of hESC-Fib to Aa serotype $c$ was associated with significant upregulation and production of IL-8 compared to Aa serotype $b$ but had no differential effect on IL-1 $\beta$ and IL-6 expression (Figures 6 and 7). In contrast, the A. actinomycetemcomitans serotype-dependent variability in cytokine expression was not observed among hESC-MSCs. The discrepancy between hPLFs and hESC-Fib in response to the Aa serotypes might be due to various reasons. Considering the origin from hESCs, hESC-Fib might still be immature compared to hPLFs. Secondly, hPLFs could be primed to bacterial challenge in vivo, while hESC-Fib are a naïve population of fibroblasts without any prior exposure to bacteria.

These results indicate that $A a$ serotype $\mathrm{c}$ induces stronger cytokine expression among fibroblasts compared to $\mathrm{Aa}$ serotype $b$, while on the contrary hESC-MSCs are largely nonresponsive to both serotypes of A. actinomycetemcomitans. However, future studies on the effect on other downstream pathways need to be validated.

\section{Discussion}

In the present study, hESC-derived progenies (hESC-Fib and hESC-MSCs) were obtained through directed differentiation of hESCs. Then, we investigated the effects of heat-killed $P$. gingivalis and A. actinomycetemcomitans on cell viability, TLRs, and cytokine expression profile of human periodontal ligament fibroblasts (hPLFs) and hESC-derived progenies, namely, fibroblasts (hESC-Fib) and MSCs (hESC-MSCs). The impact of different periodontopathogens on hPLFs and hESC-derived progenies seems to be dependent on the cell type and, to a certain extent, the strain of the periodontopathogen itself.

Among the three cell types investigated, hESC-MSCs had distinctly different response to periodontopathogens. 

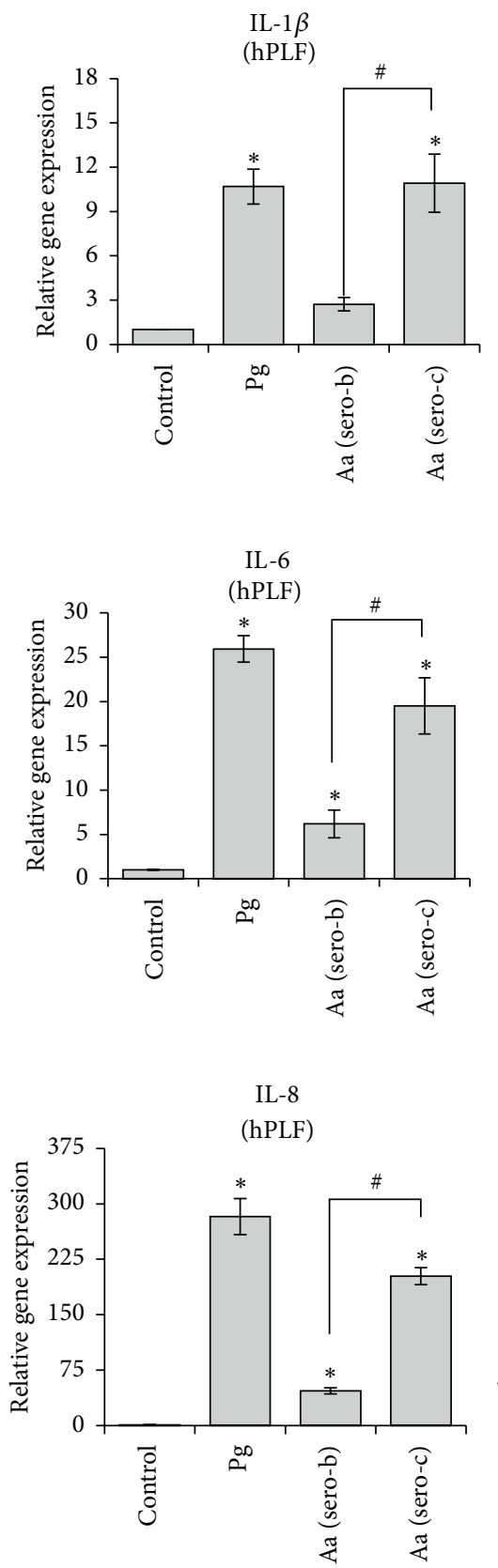

IL-1 $\beta$

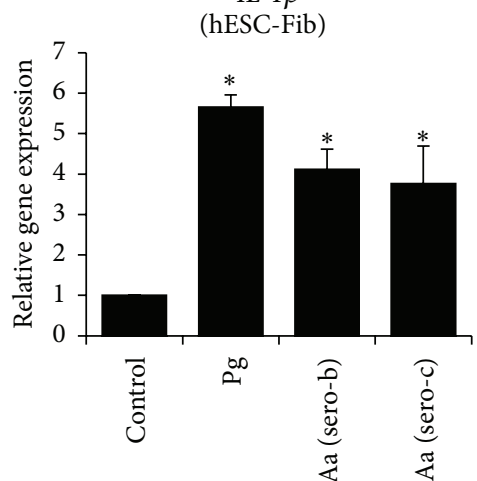

(a)

IL-6

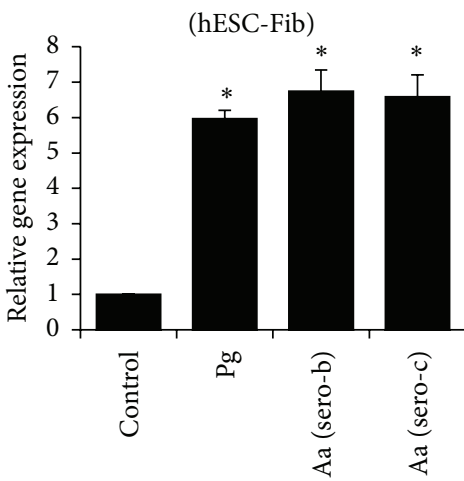

(b)

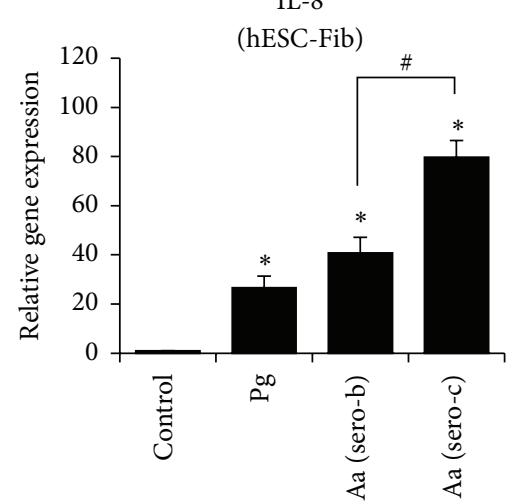

IL- $1 \beta$

(hESC-MSC)

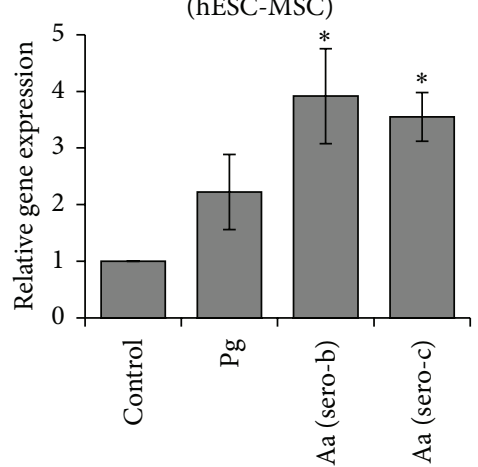

IL-6

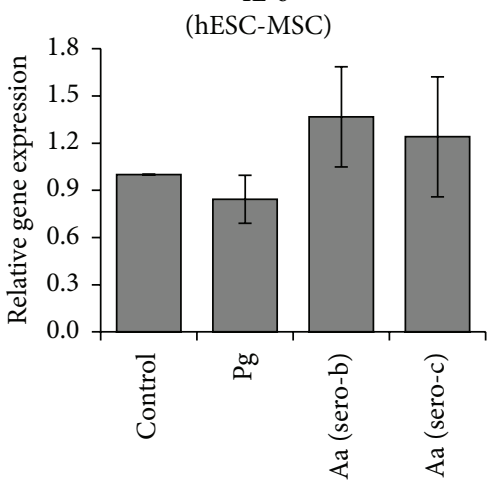

IL-8

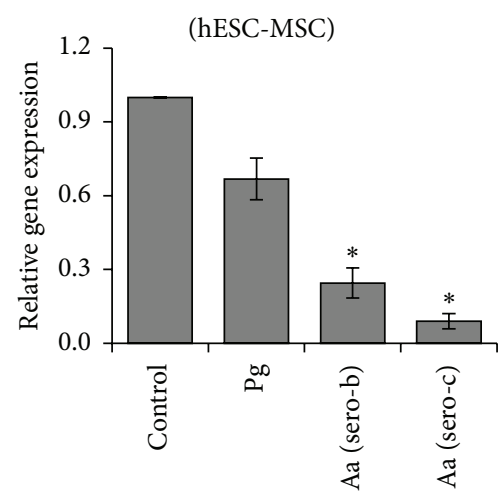

(c)

FIgURE 6: Transcript expression profiles of cytokines IL-1 $\beta$ (a), IL-6 (b), and IL-8 (c) among hPLFs, hESC-Fib, and hESC-MSCs in response to $P$. gingivalis $(\mathrm{Pg})$ and two different serotypes of A. actinomycetemcomitans (Aa serotypes $\mathrm{b}$ and $\mathrm{c}$ ). The transcript levels were normalized to the respective $\beta$-actin levels and to the untreated control sample. Values represent the means $\pm \mathrm{SD}$ of three experiments $\left({ }^{*} p<0.05\right.$ versus untreated control; ${ }^{\#} p<0.05$ versus different serotypes of $A$. actinomycetemcomitans).

Particularly, hESC-MSCs displayed a low immunogenic profile after exposure to periodontopathogens, featuring absence of changes in the expression levels of TLR-4 and cytokines (IL-6 and IL-8). Even though the hESC-MSCs expressed $T L R-2$ and TLR-4 constitutively, there was no change in TLR-inducible cytokines, indicating ineffective downstream signaling. $\mathrm{Fu}$ et al. demonstrated that hESC-MSCs share similar immunogenicity and immunoresponsive abilities like bone marrow-derived MSCs, but they exhibit differences in the expression of immunological markers and response to inflammatory cytokines suggesting that hESC-MSCs could be a potential candidate for stem cell therapy in inflammatory disorders [30].

Challenge of gingival and periodontal fibroblasts with putative periodontopathogens or their antigenic components has been reported to upregulate the immunoregulatory modulators such as IL-1 $\beta$, IL-6, and IL-8 [37-39]. Dysregulated production of these immunoregulatory molecules 

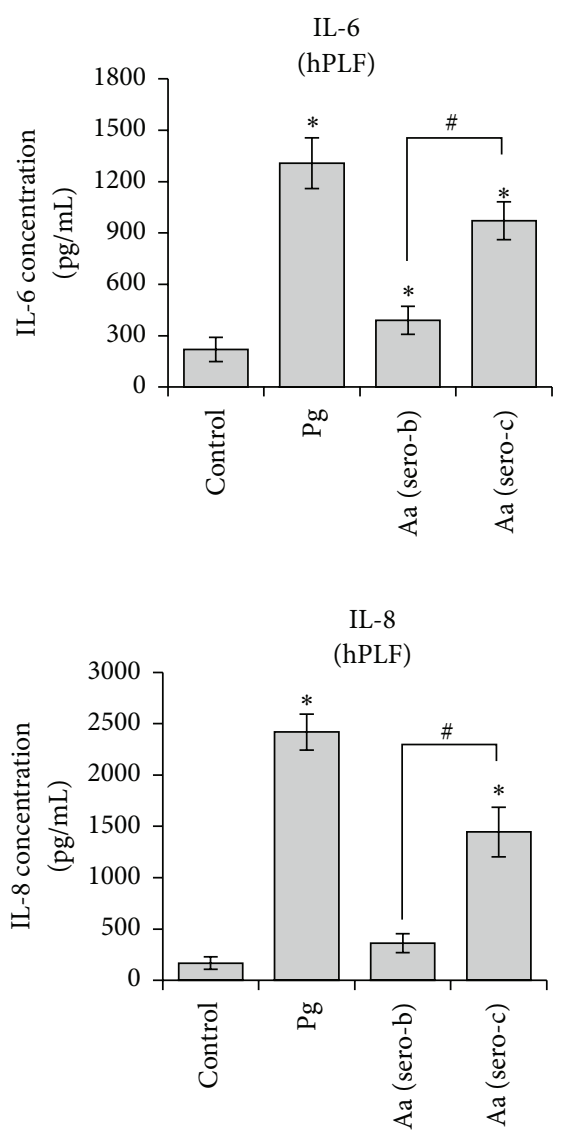

IL-6

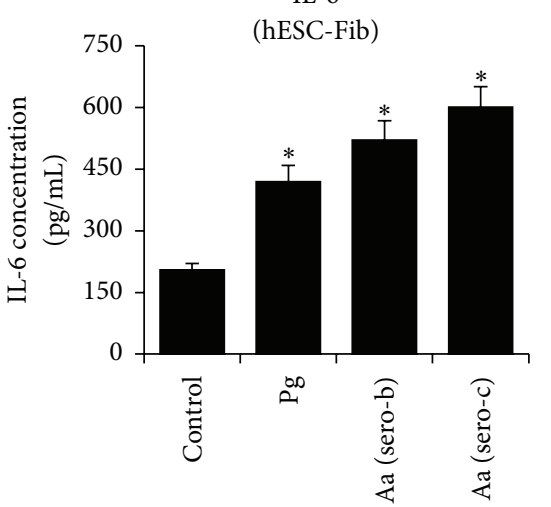

(a)

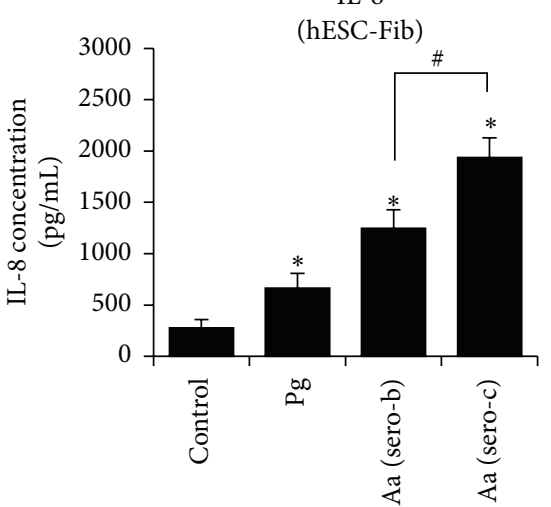

IL-6

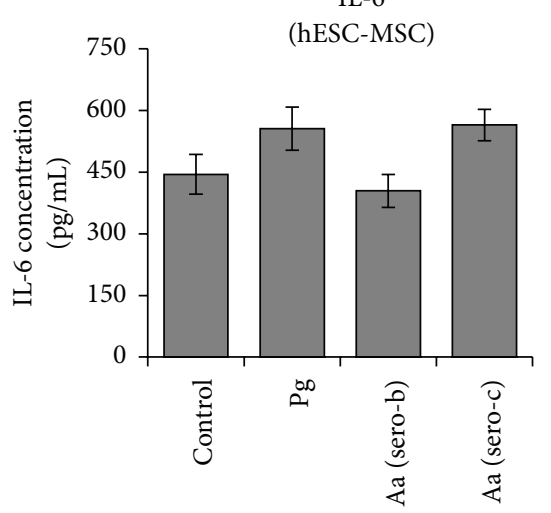

(b)

FIGURE 7: IL-6 (a) and IL-8 (b) production in the culture supernatants (assayed using ELISA) from hPLFs, hESC-Fib, and hESC-MSCs in response to exposure to P. gingivalis ( $\mathrm{Pg}$ ) and two different serotypes of A. actinomycetemcomitans (Aa serotypes b and c). Values represent the means \pm SD of three experiments $\left({ }^{*} p<0.05\right.$ versus untreated control; ${ }^{*} p<0.05$ versus different serotypes of A. actinomycetemcomitans).

in response to periodontopathogen exposure may result in excessive amplification of immune response and hence play a crucial role in periodontal tissue destruction [6, 40]. Data in the present study indicate that unchallenged hPLF, hESC-Fib, and hESC-MSCs maintained in culture for 24 hours are capable of secreting IL-1 $\beta$, IL-6, and IL8. Interestingly, unchallenged hPLFs and hESC-Fib secrete low levels of IL-6 and IL-8, while hESC-MSCs secrete high levels of both cytokines. The present study has shown that putative periodontopathogens can differentially alter the magnitude of cytokines production by hPLF, hESC-Fib, and hESC-MSCs. Upregulation of TLRs and cytokine production by hPLFs and hESC-Fib in response to $P$. gingivalis and A. actinomycetemcomitans exemplifies the ability of these fibroblasts to respond to and influence the outcome of the inflammatory response during the progression of periodontal disease. On the other hand, absence of cytokine response in hESC-MSCs indicates the differential response of these cells under bacterial challenge that could alter the progression of periodontal disease differently. A. actinomycetemcomitans has been associated with aggressive forms of periodontitis, and one possible mechanism whereby this pathogen could contribute to rapid destruction of periodontal tissues is by stimulating the fibroblasts to produce IL-6 and IL-8 [41]. Cytokines like IL- $1 \alpha$, IL- $1 \beta$, IL-6, IL- 8 , and TNF- $\alpha$ have been documented to be involved in immune activation, increased cytotoxic activity, and cytokine-mediated osteoclastic bone resorption in aggressive forms of periodontitis [10, 42-44]. The absence of stimulatory effects on hESC-MSCs could positively influence the progression of aggressive periodontal disease. However, the relevance of high levels of constitutive expression of cytokines by hESC-MSCs and their role in cellular therapy warrants further investigation.

TLR and cytokine expression profiles of hESC-Fib and hESC-MSCs in response to periodontopathogens have not been described previously. Studies on hESC-derived progenies reported that undifferentiated hESCs, hESC-derived cardiomyocytes, and endothelial cells (ECs) were nonresponsive to bacterial challenge [45]. Further, ECs derived from primary adult or fetal vessels and from stem cells like blood progenitors and induced pluripotent stem cells were responsive to LPS. In contrast, the ECs derived from hESCs were not responsive $[45,46]$. Though hESC-derived ECs were found to lack functional TLR-4, they were responsive to challenge with Gram-negative bacteria through NOD1 pathway [46]. Recent studies on hESC-derived keratinocytes 
have shown that these cells express TLRs and cytokines through activation of nuclear factor $\kappa \mathrm{B}(\mathrm{NF} \kappa \mathrm{B})$ in response to exposure to $P$ gingivalis similar to a keratinocyte cell line [47]. We observed that hESCs, hESC-Fib, and hESC-MSCs constitutively expressed $T L R-2$ and $T L R-4$. In spite of the origin from the same cell source, the expression of TLRs and cytokines in response to periodontopathogens is distinctly different among hESC-Fib and hESC-MSCs. Exposure to periodontopathogens resulted in upregulation of both TLR2 and TLR-4 in hESC-Fib, but only TLR-2 in hESC-MSCs. Further, bacterial challenge of hESC-Fib was associated with upregulation of all three cytokines ( $I L-1 \beta, I L-6$, and $I L-8)$ investigated. On the other hand, bacterial challenge of hESCMSCs was associated with upregulation of $I L-1 \beta$ only.

Considering the fact that both hESC-Fib and hESCMSCs have been derived from the same cell source, the difference in TLR and cytokine expression profiles implied a phenotype-dependent response to periodontopathogens and supported the concept of immunomodulatory properties of MSCs upon bacterial challenge. Studies have shown that the immunomodulatory property of MSCs seems to depend on their origin, as differences between bone marrow, adipose tissue, and Wharton's jelly-derived MSCs were found recently $[48,49]$. These studies demonstrated the resistance of Wharton's jelly-derived MSCs to bacterial challenge compared to other postnatal sources of MSCs. This difference could be attributed to the primitive nature of Wharton's jellyderived MSCs compared to other postnatal MSCs $[48,50]$ and/or expression of nonfunctional TLRs [48]. Similarly, studies comparing PDL-SCs and bone marrow MSCs (BMMSCs) have demonstrated that LPS and/or TNF- $\alpha$ differentially decreased the osteogenic differentiation ability of PDLSCs through TLR-4-mediated NF $\kappa$ B $[51,52]$ and Wnt [53] signaling pathways. These results suggest a stronger immunomodulatory profile of BM-MSCs compared to PDLSCs which might be due to pathological alterations caused by inflammatory insults on the latter. hESCs are one of the most primitive stem cells, and hence hESC-MSCs could also be of the most primitive state similar to WJ-MSCs. Bacterial challenge of hPLFs and hESC-Fib results in increased production of cytokines similar to those reported previously in gingival and periodontal fibroblasts $[38,54,55]$. hPLFs, hESC-Fib, and hESC-MSCs constitutively expressed IL-6 and IL-8, and this production was not upregulated by bacterial challenge in hESC-MSCs contrary to hPLFs and hESC-Fib. The primitive state of hESC-MSCs and ineffective downstream TLR signaling could possibly offer lower reactivity to TLR ligands and superior immunomodulatory profile in the context of bacterial infections.

Based on the differences in the structure of lipopolysaccharides, seven different serotypes ( $\mathrm{a}-\mathrm{g}$ ) of A. actinomycetemcomitans are described [56]. The virulence potential of this bacterium appears to vary among different serotypes and certain serotypes/clonal types are associated with aggressive forms of periodontitis. The distribution patterns of different serotypes of A. actinomycetemcomitans vary among subjects of different race, ethnicity, and geographic regions [57]. In general, serotypes $\mathrm{a}-\mathrm{c}$ are more prevalent among oral isolates than serotypes $d-f$. Further, serotype $b$ appears to be associated with periodontal disease, while serotypes a and $c$ are associated with periodontal health [56, 57]. In particular, serotype b JP2 clone is strongly associated with aggressive periodontitis $[58,59]$. Among Asians, serotype c is more prevalent in periodontitis patients than serotype $b$, while among the Caucasians the serotype prevalence is the opposite [57]. A previous in vitro study using human gingival fibroblasts has demonstrated similar serotype-dependent differences in cytokine production [37]. A. actinomycetemcomitans serotypes a and $\mathrm{c}$ were less inductive in stimulating IL-6 production while they were more inductive in IL-8 production compared to serotype b (JP2 clone). All the three $A$. actinomycetemcomitans serotypes had no significant differential effect on IL- $1 \beta$ synthesis. In this in vitro study, we observed that $A$. actinomycetemcomitans serotype $c$ induced significant upregulation of $I L-1 \beta, I L-6$, and $I L-8$ compared to $A$. actinomycetemcomitans serotype b in hPLFs. However, exposure of hESC-Fib to the A. actinomycetemcomitans serotype $\mathrm{c}$ was associated with significant upregulation and production of IL-8 compared to serotype b but had no differential effect on IL-1 $\beta$ and IL-6 expression. Further, hESCMSCs had no differential effect on all the three cytokines. In addition to the serotype-dependent differences in the impending bacteria, the response to bacterial challenge seems to be dependent on the cell type involved in the immune response process.

Innate immune response to bacterial challenge has different implications for different cell lineages depending on their role against pathogens. For instance, it is essential for immune cells and ECs to sense danger signals as a part of innate immune surveillance. Hence, for cellular therapy with these cells types as either primary cells or those derived from stem cells, it would be advantageous for these cells to express a functional innate immune response to bacterial challenge [45]. However, for cells like fibroblasts and MSCs which are not directly involved in immune surveillance, the insensitivity to bacterial challenge could have alternate implications. In cellular therapy related applications, in particular periodontitis, the transplanted cells will encounter bacterial challenge, hypoxia, and inflammation. The response of these cells in this microenvironment would be crucial for both initial survival of the transplanted cells and their role in tissue regeneration. For instance, lack of TLR-2 and TLR-4 mediated responses in transplanted cardiomyocytes is predicted to increase their survival, albeit retaining their response to inflammatory cytokines in the infarcted heart [60]. Similarly, in vitro studies have shown that hypoxia enhances the LPS-induced inflammatory cytokine expression in human periodontal ligament cells $[61,62]$. Hence, the predominantly nonresponsive behaviour of hESC-MSCs to bacterial challenge found in this study could be advantageous for their survival and probably in the longer term for optimal tissue regeneration.

\section{Conclusion}

In summary, we have shown for the first time that hESCderived progenies have phenotype-dependent response to bacterial challenge. hESC-Fib respond to bacteria through 
upregulation of TLRs and cytokine release, while hESCMSCs are largely nonresponsive in spite of their constitutive TLR expression. Hence, hESC-MSCs are a promising candidate for modulating immune response in periodontitis that could influence a superior regenerative potential. Future studies on the multilineage differentiation capacity of hESCMSCs in the presence of bacterial challenge and in vivo transplantation studies are needed to validate their regenerative potential.

$\begin{array}{ll}\text { Abbreviations } & \\ \text { A. actinomycetemcomitans (Aa): } & \text { Aggregatibacter } \\ & \text { actinomycetemcomitans } \\ \text { EB: } & \begin{array}{l}\text { Humbryoid body } \\ \text { cell-derived }\end{array} \\ \text { hESC-Fib: } & \text { fibroblast-like cells } \\ & \text { Human embryonic stem } \\ \text { hESC-MSCs: } & \text { cell-derived } \\ & \text { mesenchymal stem } \\ & \text { cells-like cells } \\ & \text { Human embryonic stem } \\ \text { hESCs: } & \text { cells } \\ & \text { Interleukins } \\ \text { IL: } & \text { Lipopolysaccharides } \\ \text { LPS: } & \text { Multiplicity of infection } \\ \text { MOI: } & \text { Mesenchymal stem cells } \\ \text { MSCs: } & \text { Porphyromonas } \\ \text { P. gingivalis (Pg): } & \text { gingivalis } \\ \text { TLR: } & \text { Toll-like receptors. }\end{array}$

\section{Competing Interests}

The authors declare that they have no competing interests.

\section{Authors' Contributions}

Gopu Sriram and Vaishali Prakash Natu contributed equally to this study.

\section{Acknowledgments}

This work was partially supported by the National University Health System Research Grant (R221000085733), Singapore. Gopu Sriram was supported by NUS Research Scholarship and President Graduate Fellowship.

\section{References}

[1] B. L. Pihlstrom, B. S. Michalowicz, and N. W. Johnson, "Periodontal diseases," The Lancet, vol. 366, no. 9499, pp. 1809-1820, 2005.

[2] A. Bascones, S. Noronha, M. Gómez, P. Mota, M. A. Gónzalez Moles, and M. Villarroel Dorrego, "Tissue destruction in periodontitis: bacteria or cytokines fault?" Quintessence International, vol. 36, no. 4, pp. 299-306, 2005.

[3] R. C. Page and K. S. Kornman, "The pathogenesis of human periodontitis: an introduction," Periodontology 2000, vol. 14, pp. 9-11, 1997.
[4] Y. Behl, M. Siqueira, J. Ortiz et al., "Activation of the acquired immune response reduces coupled bone formation in response to a periodontal pathogen," Journal of Immunology, vol. 181, no. 12, pp. 8711-8718, 2008.

[5] A. D. Haffajee and S. S. Socransky, "Microbial etiological agents of destructive periodontal diseases," Periodontology 2000, vol. 5, pp. 78-111, 1994.

[6] Z. Feng and A. Weinberg, "Role of bacteria in health and disease of periodontal tissues," Periodontology 2000, vol. 40, no. 1, pp. 50-76, 2006.

[7] N. Bostanci and G. N. Belibasakis, "Porphyromonas gingivalis: an invasive and evasive opportunistic oral pathogen," FEMS Microbiology Letters, vol. 333, no. 1, pp. 1-9, 2012.

[8] M. Hans and V. M. Hans, "Toll-like receptors and their dual role in periodontitis: a review," Journal of Oral Science, vol. 53, no. 3 , pp. 263-271, 2011.

[9] T. Kawai and S. Akira, "The role of pattern-recognition receptors in innate immunity: update on toll-like receptors," Nature Immunology, vol. 11, no. 5, pp. 373-384, 2010.

[10] N. Nakamura, M. Yoshida, M. Umeda et al., "Extended exposure of lipopolysaccharide fraction from Porphyromonas gingivalis facilitates mononuclear cell adhesion to vascular endothelium via Toll-like receptor-2 dependent mechanism," Atherosclerosis, vol. 196, no. 1, pp. 59-67, 2008.

[11] G. Matera, V. Muto, M. Vinci et al., "Receptor recognition of and immune intracellular pathways for Veillonella parvula lipopolysaccharide," Clinical and Vaccine Immunology, vol. 16, no. 12, pp. 1804-1809, 2009.

[12] D. E. Gaddis, S. M. Michalek, and J. Katz, "Requirement of TLR4 and CD14 in dendritic cell activation by Hemagglutinin B from Porphyromonas gingivalis," Molecular Immunology, vol. 46, no. 13, pp. 2493-2504, 2009.

[13] A. Uehara and H. Takada, "Functional TLRs and NODs in human gingival fibroblasts," Journal of Dental Research, vol. 86, no. 3, pp. 249-254, 2007.

[14] T. M. Schaefer, K. Desouza, J. V. Fahey, K. W. Beagley, and C. R. Wira, "Toll-like receptor (TLR) expression and TLR-mediated cytokine/chemokine production by human uterine epithelial cells," Immunology, vol. 112, no. 3, pp. 428-436, 2004.

[15] D. T. Graves and D. Cochran, "The contribution of interleukin1 and tumor necrosis factor to periodontal tissue destruction," Journal of Periodontology, vol. 74, no. 3, pp. 391-401, 2003.

[16] X. Chen, G. Wu, Z. Feng et al., "Advanced biomaterials and their potential applications in the treatment of periodontal disease," Critical Reviews in Biotechnology, vol. 36, no. 4, pp. 760-775, 2016.

[17] D. L. Cochran, C. M. Cobb, J. D. Bashutski et al., "Emerging regenerative approaches for periodontal reconstruction: a consensus report from the AAP regeneration workshop," Journal of Periodontology, vol. 86, pp. S153-S156, 2015.

[18] L. Larsson, A. M. Decker, L. Nibali, S. P. Pilipchuk, T. Berglundh, and W. V. Giannobile, "Regenerative medicine for periodontal and peri-implant diseases," Journal of Dental Research, vol. 95, no. 3, pp. 255-266, 2016.

[19] H. Liu and T. Cao, "Dental application potential of mesenchymal stromal cells and embryonic stem cells," The Chinese Journal of Dental Research, vol. 13, no. 2, pp. 95-103, 2010.

[20] X. Yin, Y. Li, J. Li et al., "Generation and periodontal differentiation of human gingival fibroblasts-derived integration-free induced pluripotent stem cells," Biochemical and Biophysical Research Communications, vol. 473, no. 3, pp. 726-732, 2016. 
[21] S. H. Bassir, W. Wisitrasameewong, J. Raanan et al., "Potential for stem cell-based periodontal therapy," Journal of Cellular Physiology, vol. 231, no. 1, pp. 50-61, 2016.

[22] Y. Liu, Y. Zheng, G. Ding et al., "Periodontal ligament stem cellmediated treatment for periodontitis in miniature swine," Stem Cells, vol. 26, no. 4, pp. 1065-1073, 2008.

[23] G. Ding, Y. Liu, W. Wang et al., "Allogeneic periodontal ligament stem cell therapy for periodontitis in swine," Stem Cells, vol. 28, no. 10, pp. 1829-1838, 2010.

[24] J. A. Thomson, J. Itskovitz-Eldor, and S. S. Shapiro, "Embryonic stem cell lines derived from human blastocysts," Science, vol. 282, no. 5391, pp. 1145-1147, 1998.

[25] G. Sriram, J. Y. Tan, I. Islam, A. J. Rufaihah, and T. Cao, "Efficient differentiation of human embryonic stem cells to arterial and venous endothelial cells under feeder- and serumfree conditions," Stem Cell Research and Therapy, vol. 6, article 261, 2015.

[26] X. Fu, W. S. Toh, H. Liu et al., "Autologous feeder cells from embryoid body outgrowth support the long-term growth of human embryonic stem cells more effectively than those from direct differentiation," Tissue Engineering_Part C: Methods, vol. 16, no. 4, pp. 719-733, 2010.

[27] X. Fu, W. S. Toh, H. Liu, K. Lu, M. Li, and T. Cao, "Establishment of clinically compliant human embryonic stem cells in an autologous feeder-free system," Tissue Engineering-Part C: Methods, vol. 17, no. 9, pp. 927-937, 2011.

[28] F. K. Kidwai, M. M. Movahednia, K. Iqbal, D. S. Jokhun, T. Cao, and A. S. Fawzy, "Human embryonic stem cell differentiation into odontoblastic lineage: an in vitro study," International Endodontic Journal, vol. 47, no. 4, pp. 346-355, 2014.

[29] K. J. Vinoth, J. Manikandan, S. Sethu et al., "Evaluation of human embryonic stem cells and their differentiated fibroblastic progenies as cellular models for in vitro genotoxicity screening," Journal of Biotechnology, vol. 184, pp. 154-168, 2014.

[30] X. Fu, Y. Chen, F.-N. Xie et al., "Comparison of immunological characteristics of mesenchymal stem cells derived from human embryonic stem cells and bone marrow," Tissue EngineeringPart A, vol. 21, no. 3-4, pp. 616-626, 2015.

[31] A. J. Rufaihah, H. K. Haider, B. C. Heng et al., "Directing endothelial differentiation of human embryonic stem cells via transduction with an adenoviral vector expressing the VEGF165 gene," Journal of Gene Medicine, vol. 9, no. 6, pp. 452-461, 2007.

[32] T. Cao, K. Lu, X. Fu, and B. C. Heng, "Differentiated fibroblastic progenies of human embryonic stem cells for toxicology screening," Cloning and Stem Cells, vol. 10, no. 1, pp. 1-9, 2008.

[33] A. Saminathan, K. J. Vinoth, H. H. Low, T. Cao, and M. C. Meikle, "Engineering three-dimensional constructs of the periodontal ligament in hyaluronan-gelatin hydrogel films and a mechanically active environment," Journal of Periodontal Research, vol. 48, no. 6, pp. 790-801, 2013.

[34] A. Saminathan, G. Sriram, J. K. Vinoth, T. Cao, and M. C. Meikle, "Engineering the periodontal ligament in hyaluronangelatin-type i collagen constructs: upregulation of apoptosis and alterations in gene expression by cyclic compressive strain," Tissue Engineering-Part A, vol. 21, no. 3-4, pp. 518-529, 2015.

[35] Q. Ding, S. Y. Quah, and K. S. Tan, "Secreted ATP from A. actinomycetemcomitans triggers chemokine response," Molecular oral microbiology, 2015.

[36] M. Li, X. Li, M. C. Meikle, I. Islam, and T. Cao, "Short periods of cyclic mechanical strain enhance triple-supplement directed osteogenesis and bone nodule formation by human embryonic stem cells in vitro," Tissue Engineering - Part A, vol. 19, no. 19-20, pp. 2130-2137, 2013.

[37] A. I. Dongari-Bagtzoglou and J. L. Ebersole, "Production of inflammatory mediators and cytokines by human gingival fibroblasts following bacterial challenge," Journal of Periodontal Research, vol. 31, no. 2, pp. 90-98, 1996.

[38] Y. Sun, R. Shu, C.-L. Li, and M.-Z. Zhang, "Gram-negative periodontal bacteria induce the activation of Toll-like receptors 2 and 4, and cytokine production in human periodontal ligament cells," Journal of Periodontology, vol. 81, no. 10, pp. 1488-1496, 2010.

[39] T. D. K. Herath, Y. Wang, C. J. Seneviratne et al., "Porphyromonas gingivalis lipopolysaccharide lipid A heterogeneity differentially modulates the expression of IL-6 and IL-8 in human gingival fibroblasts," Journal of Clinical Periodontology, vol. 38, no. 8, pp. 694-701, 2011.

[40] R. C. Page, "The role of inflammatory mediators in the pathogenesis of periodontal disease," Journal of Periodontal Research, vol. 26, no. 3, pp. 230-242, 1991.

[41] D. H. Meyer and P. M. Fives-Taylor, "The role of Actinobacillus actinomycetemcomitans in the pathogenesis of periodontal disease," Trends in Microbiology, vol. 5, no. 6, pp. 224-228, 1997.

[42] J. L. Ebersole, D. R. Dawson III, L. A. Morford, R. Peyyala, C. S. Miller, and O. A. Gonzaléz, "Periodontal disease immunology: 'double indemnity' in protecting the host," Periodontology 2000, vol. 62, no. 1, pp. 163-202, 2013.

[43] G. Hajishengallis, "Immunomicrobial pathogenesis of periodontitis: keystones, pathobionts, and host response," Trends in Immunology, vol. 35, no. 1, pp. 3-11, 2014.

[44] S. A. Hienz, S. Paliwal, and S. Ivanovski, "Mechanisms of bone resorption in periodontitis," Journal of Immunology Research, vol. 2015, Article ID 615486, 10 pages, 2015.

[45] G. Földes, A. Liu, R. Badiger et al., "Innate immunity in human embryonic stem cells: comparison with adult human endothelial cells," PLoS ONE, vol. 5, no. 5, Article ID e10501, 2010.

[46] D. M. Reed, G. Foldes, T. Gatheral et al., "Pathogen sensing pathways in human embryonic stem cell derived-endothelial cells: role of NOD1 receptors," PLoS ONE, vol. 9, no. 4, Article ID e91119, 2014.

[47] F. K. Kidwai, D. S. Jokhun, M. M. Movahednia, J. F. Yeo, K. S. Tan, and T. Cao, "Human embryonic stem cells derived keratinocyte as an in vitro research model for the study of immune response," Journal of Oral Pathology and Medicine, vol. 42, no. 8, pp. 627-634, 2013.

[48] G. Raicevic, M. Najar, B. Stamatopoulos et al., "The source of human mesenchymal stromal cells influences their TLR profile as well as their functional properties," Cellular Immunology, vol. 270, no. 2, pp. 207-216, 2011.

[49] Y.-B. Mei, W.-Q. Zhou, X.-Y. Zhang, X.-J. Wei, and Z.-C. Feng, "Lipopolysaccharides shapes the human wharton's jellyderived mesenchymal stem cells in vitro," Cellular Physiology and Biochemistry, vol. 32, no. 2, pp. 390-401, 2013.

[50] D. L. Troyer and M. L. Weiss, "Concise review: wharton's Jellyderived cells are a primitive stromal cell population," Stem Cells, vol. 26, no. 3, pp. 591-599, 2008.

[51] C. Li, B. Li, Z. Dong et al., "Lipopolysaccharide differentially affects the osteogenic differentiation of periodontal ligament stem cells and bone marrow mesenchymal stem cells through Toll-like receptor 4 mediated nuclear factor $\kappa \mathrm{B}$ pathway," Stem Cell Research and Therapy, vol. 5, article 67, 2014. 
[52] J. Zhang, Z.-G. Li, Y.-M. Si, B. Chen, and J. Meng, “The difference on the osteogenic differentiation between periodontal ligament stem cells and bone marrow mesenchymal stem cells under inflammatory microenviroments," Differentiation, vol. 88, no. 4-5, pp. 97-105, 2014.

[53] W. Liu, A. Konermann, T. Guo, A. Jäger, L. Zhang, and Y. Jin, "Canonical Wnt signaling differently modulates osteogenic differentiation of mesenchymal stem cells derived from bone marrow and from periodontal ligament under inflammatory conditions," Biochimica et Biophysica Acta-General Subjects, vol. 1840, no. 3, pp. 1125-1134, 2014.

[54] N. Scheres, M. L. Laine, P. M. Sipos et al., "Periodontal ligament and gingival fibroblasts from periodontitis patients are more active in interaction with Porphyromonas gingivalis," Journal of Periodontal Research, vol. 46, no. 4, pp. 407-416, 2011.

[55] K. J. Baek, Y. Choi, and S. Ji, "Gingival fibroblasts from periodontitis patients exhibit inflammatory characteristics in vitro," Archives of Oral Biology, vol. 58, no. 10, pp. 1282-1292, 2013.

[56] C. H. Åberg, P. Kelk, and A. Johansson, "Aggregatibacter actinomycetemcomitans: virulence of its leukotoxin and association with aggressive periodontitis," Virulence, vol. 6, no. 3, pp. 188195, 2015.

[57] J.-A. Brígido, V.-R. da Silveira, R.-O. Rego, and N.-A. Nogueira, "Serotypes of Aggregatibacter actinomycetemcomitans in relation to periodontal status and geographic origin of individuals-a review of the literature," Medicina Oral, Patologia Oral y Cirugia Bucal, vol. 19, no. 2, pp. 184-191, 2014.

[58] D. Haubek, O.-K. Ennibi, K. Poulsen, M. Væth, S. Poulsen, and M. Kilian, "Risk of aggressive periodontitis in adolescent carriers of the JP2 clone of Aggregatibacter (Actinobacillus) actinomycetemcomitans in Morocco: a prospective longitudinal cohort study," The Lancet, vol. 371, no. 9608, pp. 237-242, 2008.

[59] C. Höglund Åberg, F. Kwamin, R. Claesson, G. Dahlén, A. Johansson, and D. Haubek, "Progression of attachment loss is strongly associated with presence of the JP2 genotype of Aggregatibacter actinomycetemcomitans: a prospective cohort study of a young adolescent population," Journal of Clinical Periodontology, vol. 41, no. 3, pp. 232-241, 2014.

[60] S. Frantz, G. Ertl, and J. Bauersachs, "Mechanisms of disease: toll-like receptors in cardiovascular disease," Nature Clinical Practice Cardiovascular Medicine, vol. 4, no. 8, pp. 444-454, 2007.

[61] L. Gölz, S. Memmert, B. Rath-Deschner et al., "Hypoxia and $P$. gingivalis synergistically induce HIF-1 and NF- $\kappa$ B activation in PDL cells and periodontal diseases," Mediators of Inflammation, vol. 2015, Article ID 438085, 12 pages, 2015.

[62] C. Jian, C. Li, Y. Ren et al., "Hypoxia augments lipopolysaccharide-induced cytokine expression in periodontal ligament cells," Inflammation, vol. 37, no. 5, pp. 1413-1423, 2014. 

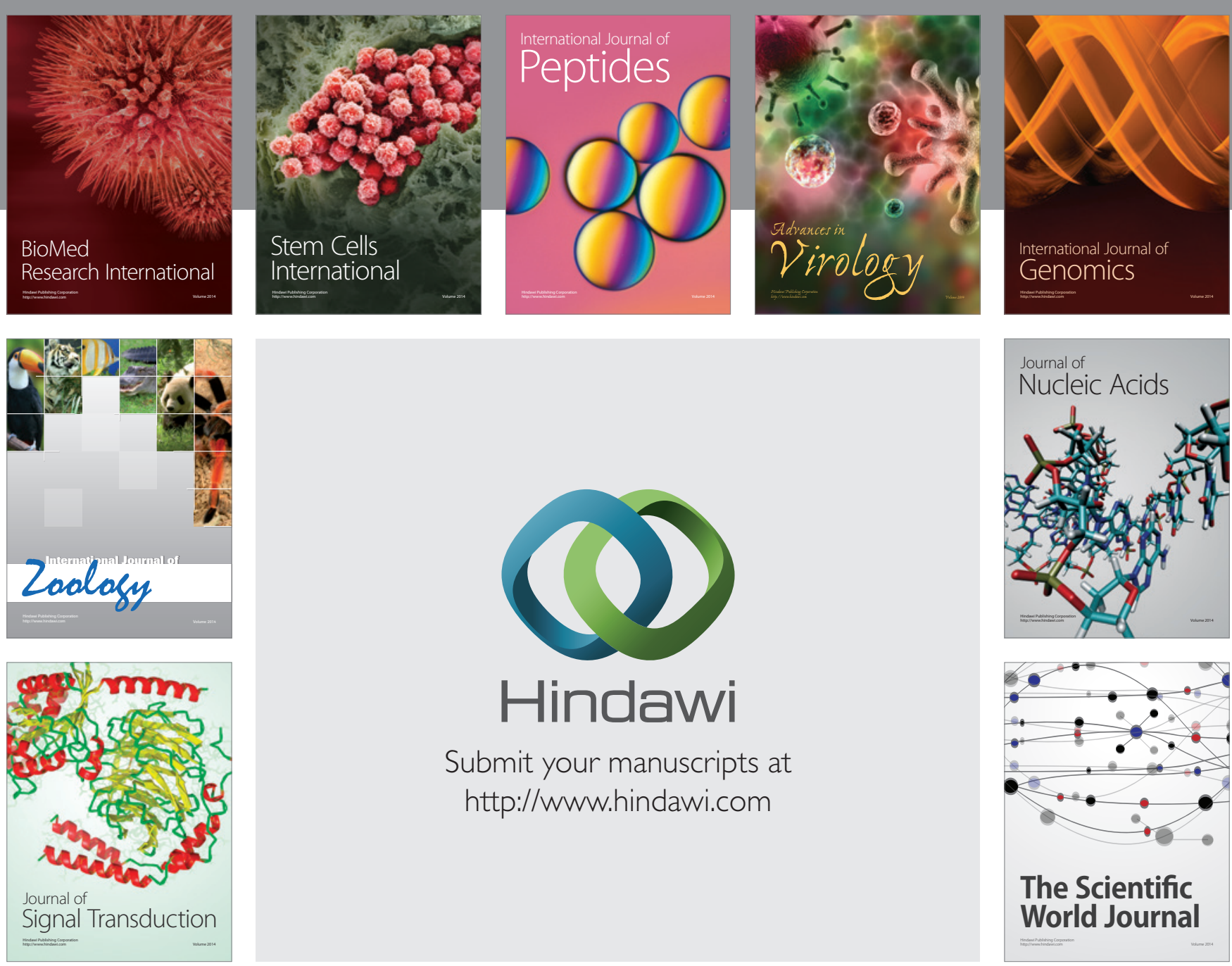

Submit your manuscripts at

http://www.hindawi.com
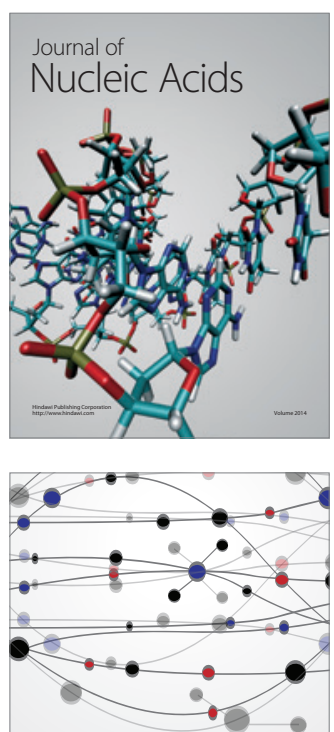

The Scientific World Journal
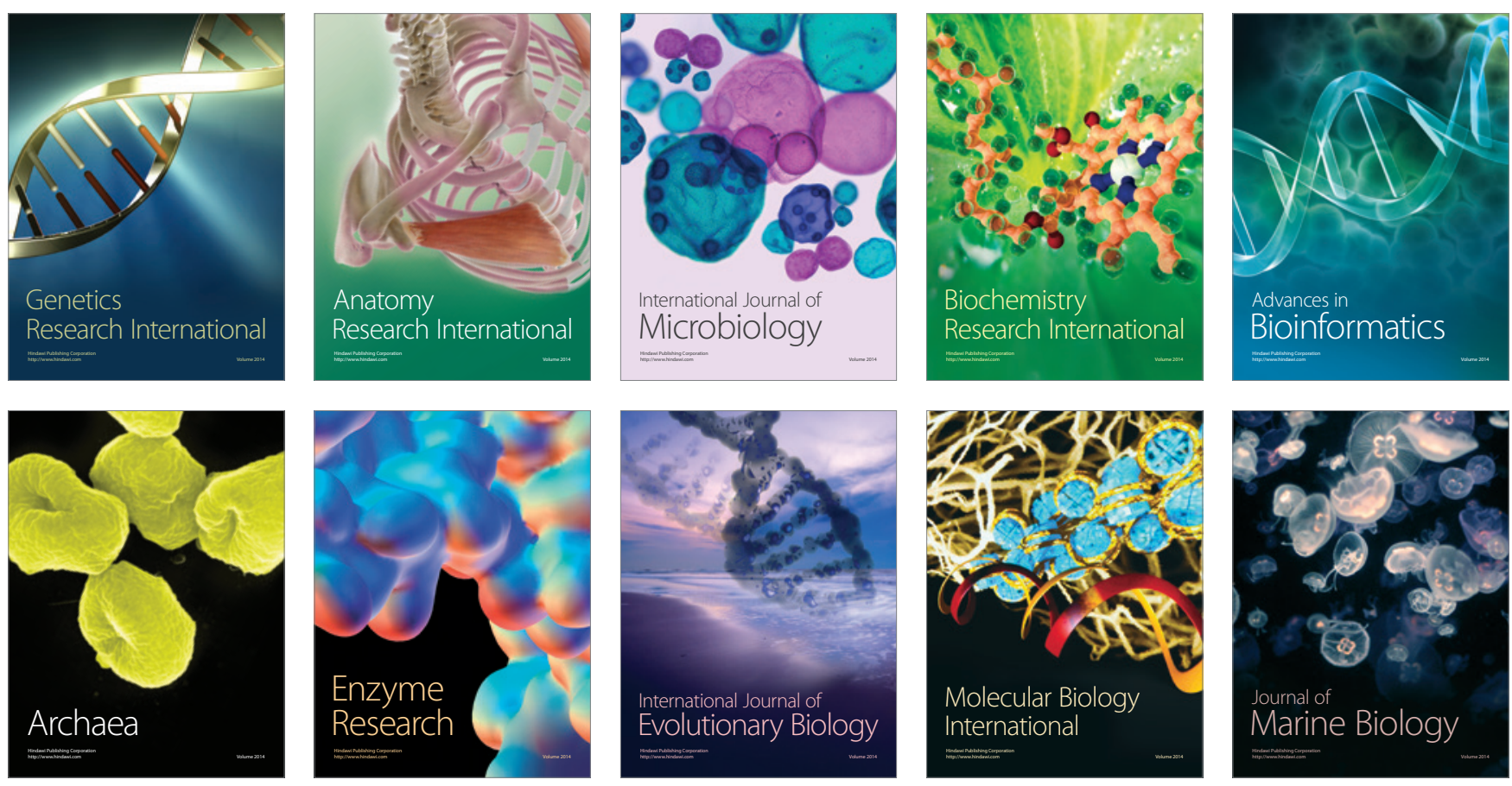